OPEN ACCESS

Edited by: Dirk M. Hermann, University of Duisburg-Essen,

Germany

Reviewed by:

Egor Dzyubenko,

Essen University Hospital, Germany

Jinwei Zhang,

University of Exeter, United Kingdom

*Correspondence:

Melanie A. Woodin

m.woodin@utoronto.ca

Specialty section:

This article was submitted to

Cellular Neurophysiology,

a section of the journal

Frontiers in Cellular Neuroscience

Received: 17 November 2021

Accepted: 24 December 2021

Published: 14 January 2022

Citation:

Serranilla M and Woodin MA (2022) Striatal Chloride Dysregulation and Impaired GABAergic Signaling Due to Cation-Chloride Cotransporter

Dysfunction in Huntington's Disease. Front. Cell. Neurosci. 15:817013. doi: 10.3389/fncel.2021.817013

\section{Striatal Chloride Dysregulation and Impaired GABAergic Signaling Due to Cation-Chloride Cotransporter Dysfunction in Huntington's Disease}

\author{
Melissa Serranilla and Melanie A. Woodin* \\ Department of Cell and Systems Biology, University of Toronto, Toronto, ON, Canada
}

Intracellular chloride $\left(\mathrm{Cl}^{-}\right)$levels in mature neurons must be tightly regulated for the maintenance of fast synaptic inhibition. In the mature central nervous system (CNS), synaptic inhibition is primarily mediated by gamma-amino butyric acid (GABA), which binds to $\mathrm{Cl}^{-}$permeable $\mathrm{GABA}_{A}$ receptors $\left(\mathrm{GABA}_{A} \mathrm{Rs}\right)$. The intracellular $\mathrm{Cl}^{-}$ concentration is primarily maintained by the antagonistic actions of two cation-chloride cotransporters (CCCs): $\mathrm{Cl}^{-}$-importing $\mathrm{Na}^{+}-\mathrm{K}^{+}-\mathrm{Cl}^{-}$co-transporter-1 (NKCC1) and $\mathrm{Cl}^{-}$ -exporting $\mathrm{K}^{+}-\mathrm{Cl}^{-}$co-transporter-2 (KCC2). In mature neurons in the healthy brain, KCC2 expression is higher than NKCC1, leading to lower levels of intracellular $\mathrm{Cl}^{-}$, and $\mathrm{Cl}^{-}$influx upon $\mathrm{GABA}_{A} \mathrm{R}$ activation. However, in neurons of the immature brain or in neurological disorders such as epilepsy and traumatic brain injury, impaired KCC2 function and/or enhanced NKCC1 expression lead to intracellular $\mathrm{Cl}^{-}$accumulation and GABA-mediated excitation. In Huntington's disease (HD), KCC2- and NKCC1mediated $\mathrm{Cl}^{-}$-regulation are also altered, which leads to GABA-mediated excitation and contributes to the development of cognitive and motor impairments. This review summarizes the role of $\mathrm{Cl}^{-}$(dys)regulation in the healthy and $\mathrm{HD}$ brain, with a focus on the basal ganglia (BG) circuitry and CCCs as potential therapeutic targets in the treatment of HD.

Keywords: KCC2, chloride regulation, GABA, synaptic inhibition, striatum, Huntington's disease

\section{INTRODUCTION}

Huntington's disease (HD) is an inherited neurodegenerative disorder characterized by involuntary choreatic movements, cognitive disturbances, and mood disorders (Ghosh and Tabrizi, 2018). HD is caused by a triple cytosine-adenine-guanine (CAG) repeat expansion in the gene encoding for the ubiquitously expressed Huntingtin (Htt) protein (The Huntington's Disease Collaborative Research Group, 1993), with the CAG repeat length corresponding to the age of onset and disease severity (Snell et al., 1993). HD is primarily characterized by progressive motor incoordination as earlier stages of the disease include involuntary movement (chorea), while late stages are characterized by progressive hypokinesia and bradykinesia (Huntington, 1872). These biphasic changes that occur during disease progression result from differential susceptibility in the direct and indirect pathways of basal ganglia (BG) circuitry (Albin et al., 1992). The direct and indirect pathways exert opposing effects on BG output, activation of the direct pathway promotes movement while activation of the indirect pathway inhibits unwanted movements (Alexander and Crutcher, 1990). 
In HD, gamma-amino butyric acid (GABA)-releasing medium spiny neurons (MSNs) of the indirect pathway, which primarily express the D2 dopamine receptor (D2-MSNs) demonstrate an enhanced susceptibility to neurodegeneration, leading to the development of chorea (Albin et al., 1992). At late stages of the disease, MSNs of the direct pathway which primarily express the D1 dopamine receptor (D1-MSNs) also degenerate leading to rigidity and hypokinesia (Thompson et al., 1988).

Impaired GABAergic signaling directly contributes to the cognitive and motor deficits associated with HD, and results in part from alterations in two cation-chloride cotransporters (CCCs): $\mathrm{Na}^{+}-\mathrm{K}^{+}-\mathrm{Cl}^{-}$co-transporter-1 (NKCC1) and $\mathrm{K}^{+}-\mathrm{Cl}^{-}$ co-transporter-2 (KCC2). In mouse models of HD, NKCC1 and KCC2 are altered in the hippocampus and striatum, which results in weakened inhibition and paradoxical excitatory actions of GABA (Dargaei et al., 2018; Hsu et al., 2019). In this review, we highlight $\mathrm{Cl}^{-}$regulation by CCCs and its impact on GABA signaling to explore the potential mechanisms underlying CCC dysfunction in $\mathrm{HD}$. We start by reviewing: $\mathrm{HD}, \mathrm{CCCs}, \mathrm{Cl}^{-}$ dynamics and GABAergic transmission in the BG of healthy and HD brains. Lastly, we consider why existing drugs targeting GABA signaling may have failed in treating HD (Shoulson et al., 1977; Foster et al., 1983) and how targeting CCCs may prove to be a better alternative for restoring inhibitory function in this devastating neurodegenerative disease.

\section{HUNTINGTON'S DISEASE}

\section{Overview}

The first description of HD dates as early as 1842 , but it was not until 1872, that it became known as Huntington's chorea, which refers to the rapid and irregular movements first observed (Huntington, 1872). Motor symptoms begin as hyperkinetic movements which decrease as patients develop bradykinesia and rigidity, however, in later stages HD patients experience severe hypokinesia and an akinetic state (Sturrock and Leavitt, 2010). The psychiatric symptoms associated with $\mathrm{HD}$ are highly variable and precede motor symptoms by $\sim 10-15$ years, making it difficult to diagnose HD without genetic tests.

Huntington's disease is caused by a mutation in the gene (HTT) encoding the protein huntingtin $(\mathrm{Htt})$ on chromosome 4. The HTT mutation is a repeat expansion of cytosine-adenineguanine (CAG) which encodes for the amino acid glutamine in the first exon (The Huntington's Disease Collaborative Research Group, 1993). CAG repeat length is inversely correlated with age of disease onset and symptom severity, with healthy individuals having 35 or fewer CAG repeats while HD gene carriers contain 36 or more CAG repeats. Over $60 \mathrm{CAG}$ repeats leads to the development of juvenile-onset HD, which occurs in 5-10\% of HD patients and is associated with increased severity (Andrew et al., 1993; Figure 1A). This CAG repeat expansion gives rise to an aberrantly long polyglutamine stretch in the mutant huntingtin (mHtt), causing the protein to misfold and to obtain toxic properties (Alexander and Crutcher, 1990) (Figure 1B). Despite the ubiquitous expression of $\mathrm{mHtt}$ throughout the brain of $\mathrm{HD}$ patients, neurodegeneration is specific to certain brain regions such as the striatum, cerebral cortex, and hippocampus (Reiner et al., 1988; Spargo et al., 1993).

Current therapeutic approaches are limited by the late detection of the disease, which primarily relies on the presence of motor impairments, although recently more sensitive methods have been developed to evaluate subtle disturbances in HD (Paulsen et al., 2008). Without direct targeting of $\mathrm{mHtt}$, the current treatments are limited to targeting and mitigating symptoms, which include speech and physical therapies (Dickey and La Spada, 2018) and modulators of dopaminergic signaling such as tetrabenazine to treat motor symptoms (Jankovic and Clarence-Smith, 2011). While the use of Antisense Oligonucleotides (ASOs), RNA Interference, RNA Splicing Modification and DNA Repair Proteins (Wiggins and Feigin, 2021) hold some promise, clinical trials do not include premanifest HD patients or those with the early-onset juvenile HD (Wiggins and Feigin, 2021), further impeding the development of HD therapeutic strategies. As we discuss below, CCCs have only recently emerged as a potential therapeutic target and have proven to be beneficial in both presymptomatic and symptomatic HD mice (Dargaei et al., 2018; Hsu et al., 2019), providing a novel strategy to combat this devastating disease.

\section{Interactors of Huntingtin and $\mathrm{K}^{+}-\mathrm{Cl}^{-}$ Co-transporter-2 Are Altered in Huntington's Disease}

Although the HD mutation has been well-characterized, the mechanism by which $\mathrm{mHtt}$ protein leads to a specific pattern of synaptic dysfunction remain elusive. Normal $\mathrm{Htt}$ is a multidomain protein with no sequence homology with other proteins, thus efforts to find its exact functions have relied on examining interacting proteins (Harjes and Wanker, 2003). Htt has over 200 protein interactors that have functions in: cellular dynamics, metabolism, protein turnover, and gene expression (Saudou and Humbert, 2016), which suggests that Htt may be a molecular scaffold that tethers multiple partners into complexes necessary for various signaling processes. With the many functions of $\mathrm{Htt}$ and large number of interacting proteins, we highlight only those relevant to CCC activity and inhibitory synaptic transmission. For example, an important regulator of KCC2 transcription is brain-derived neurotrophic factor (BDNF), an essential neurotrophin for the proper functioning of cortico-striatal synapses (Nakao et al., 1995). BDNF production and trafficking in the striatum are regulated by $\mathrm{Htt}$ and are well studied in HD (Zuccato et al., 2003). BDNF transcripts contain DNA repressor elements (RE1), also referred to as neuron-restrictive silencer element (NRSE) sequences, which is recognized by the transcriptional silencer RE-1 silencing transcription factor (REST), also known as neuronal restrictive silencing factor, (NRSF) (Maue et al., 1990). Normal Htt promotes $B d n f$ transcription by sequestering REST/NRSF in the cytoplasm, thus preventing it from forming the nuclear corepressor complex at the RE/NRSE nuclear site, thereby allowing BDNF transcription to take place. In contrast, $\mathrm{mHtt}$ allows entry of REST/NRSF into the nucleus, thereby reducing $b d n f$ transcription (Zuccato et al., 2003). 

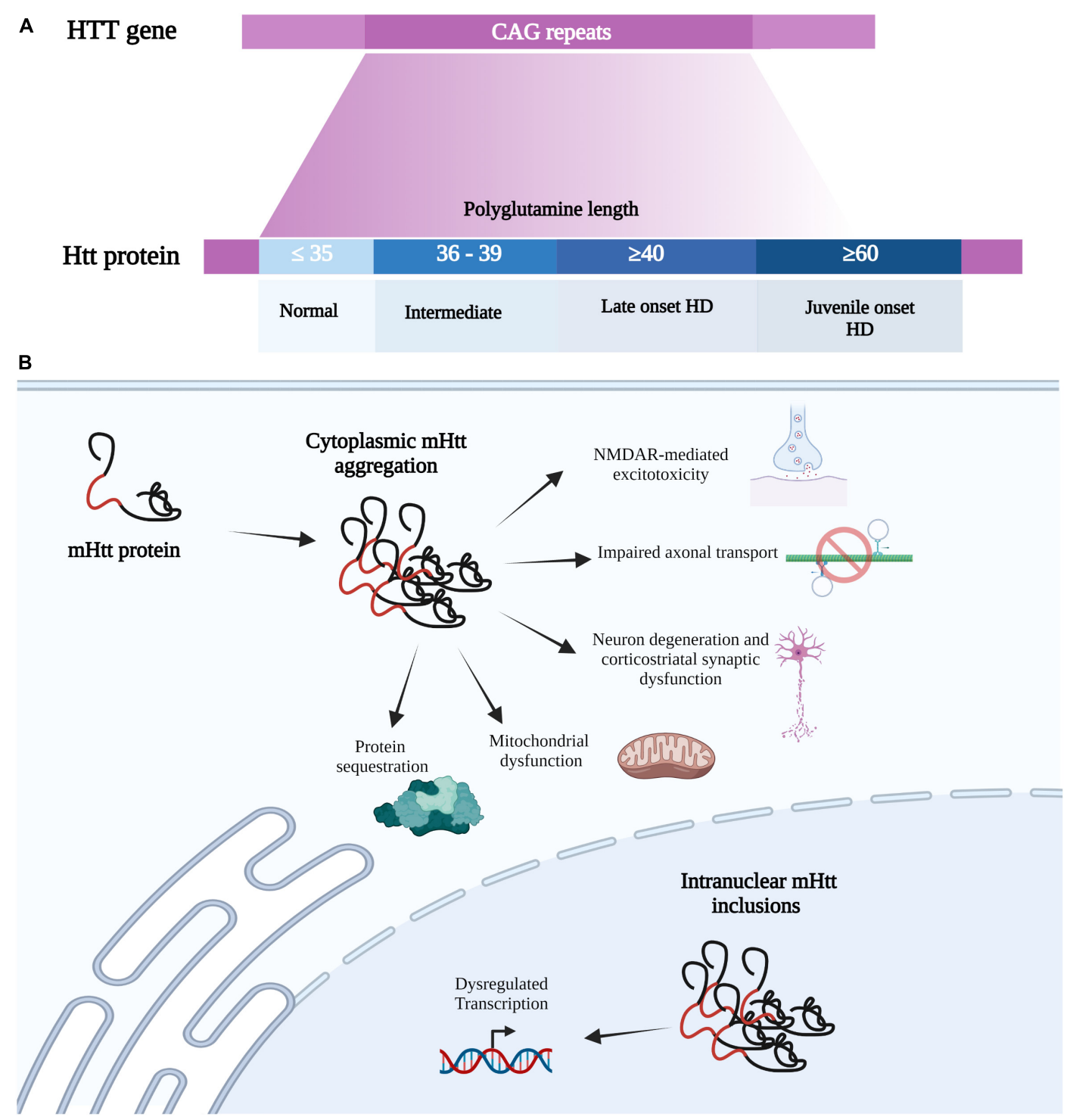

FIGURE 1 | Huntington's disease mutation and HD-associated cellular impairments. (A) HD is a caused by a mutation in the HTT gene on chromosome 4, which consists of CAG (cytosine-adenine-guanine) trinucleotide repeats which encode for a glutamine. The HTT mutation is an expanded CAG, where normal individuals contain 35 or fewer CAG repeats while HD carriers contain 36 or more. CAG repeat length is inversely correlated with disease onset and symptom severity, with over 60 CAG repeats leading to juvenile-onset HD. The CAG repeat expansion gives rise to an aberrantly long polyglutamine stretch in the mutant huntingtin protein $(\mathrm{mHtt})$, causing the protein to misfold and obtain toxic properties. (B) $\mathrm{mHtt}$ can form insoluble aggregates in the cytosol and nucleus to produce various toxic effects. As normal $\mathrm{Htt}$ has multiple binding partners, $\mathrm{mHTT}$ can sequester these proteins into these $\mathrm{mHtt}$ aggregates. $\mathrm{mHtt}$ aggregation also causes mitochondrial dysfunction, neuron degeneration (primarily at corticostriatal synapses), impairs axonal transport, and mediates glutamate toxicity. mHtt can also be translocated into the nucleus to form Intranuclear $\mathrm{mHtt}$ inclusion, which lead to dysregulation transcription. Created with BioRender.com.

Another important regulator of KCC2 activity that is altered in $\mathrm{HD}$ is protein kinase $\mathrm{C}$ and casein kinase II substrate in neurons (PACSIN1) (Mahadevan et al., 2017). Htt interacts with PACSIN1, which regulates post-synaptic expression of N-methylD-aspartate receptors (NMDARs) by removing the immature GluN3A subunits necessary for the incorporation of more mature subunits in the membrane (Modregger et al., 2002). This prevents premature synapse plasticity and provides stability during early stages of postnatal brain development (Pérez-Otaño et al., 2006). In $\mathrm{HD}, \mathrm{mHtt}$ sequesters PACSIN1, causing accumulation of
GluN3A-containing NMDARs at the surface of striatal neurons leading to synapse destabilization and synaptic degeneration in HD (Marco et al., 2013).

\section{Huntington's Disease Impacts Neurodevelopment}

Huntington's disease is largely considered a neurodegenerative disease, with very little impact on development due to late onset of symptoms and the ability of $\mathrm{mHtt}$ expression to rescue 
embryonic lethality in HTT-null mice (Zeitlin et al., 1995; Leavitt et al., 2001). However, the HD mutation is now known to produce neurodevelopmental defects, suggesting that the disease is much more complex (Barnat et al., 2017; Barnat et al., 2020; Capizzi et al., 2021). Htt is required for the multipolarbipolar transition and migration of projection neurons, and in HD newborn cortical neural migration is disrupted (Barnat et al., 2017). At 13-week gestation in the fetal cortex, junctional complex proteins (in addition to $\mathrm{mHtt}$ ) are mislocalized and neural progenitor cell polarity and differentiation are defective, leading to premature entry of neural progenitors entering lineage specification (Barnat et al., 2017), which has led to the suggestion that $\mathrm{Htt}$ maintains epithelial cell polarity throughout the body. In addition, a recent study reported that layer II/III neurons exhibit defects in microtubule bundling leading to limited axonal growth during development (Capizzi et al., 2021). The disorganization of microtubules is due to the downregulation of nuclear mitotic apparatus protein 1 (NUMA1), which plays a role in the proper formation and organization of mitotic spindles during cell division (Kiyomitsu and Boerner, 2021). Due to the limited axonal growth, fewer axons cross the corpus callosum, which normally connect the two hemispheres. It is now evident that the HD mutation disrupts fundamental processes during neurodevelopment such as neurogenesis, neural migration, and axonal growth.

Although this review focuses on CCC dysfunction in mature neurons, the neurodevelopmental defects in $\mathrm{HD}$ and the importance of GABA signaling during the development of neural networks (Ben-Ari, 2002) presents the possibility that in $\mathrm{HD}$, specific neurons may have failed to undergo the necessary "developmental switch" in GABA polarity, which we describe below.

\section{CATION-CHLORIDE CO-TRANSPORTERS, CHLORIDE REGULATION AND SYNAPTIC INHIBITION}

\section{Overview}

Gamma-amino butyric acid is the main inhibitory neurotransmitter in the mature central nervous system (CNS), which mediates fast GABAergic inhibition by binding to $\mathrm{GABA}_{\mathrm{A}}$ Rs. $\mathrm{GABA}_{\mathrm{A}}$ Rs are permeable to $\mathrm{Cl}^{-}$and $\mathrm{HCO}_{3}{ }^{-}$and therefore the reversal potential of $\mathrm{GABA}_{\mathrm{A}} \mathrm{R}$ currents $\left(\mathrm{E}_{\mathrm{GABA}}\right)$ is determined by the equilibrium potentials of $\mathrm{Cl}^{-}\left(\mathrm{E}_{\mathrm{Cl}}\right)$ and $\mathrm{HCO}_{3}{ }^{-}\left(\mathrm{E}_{\mathrm{HCO}}\right)$ (Figure 2; Kaila et al., 1989; Kaila, 1994). The equilibrium potential for a particular ion is the membrane potential at which there is no net flow of that ion and can be calculated from the Nernst equation (if the intra- and extracellular concentrations are known). In healthy mature neurons, $\mathrm{E}_{\mathrm{Cl}}$ is usually slightly hyperpolarized with respect to the resting membrane potential, while $\mathrm{E}_{\mathrm{HCO}}$ is depolarized, ranging from $-40 \mathrm{mV}$ to $-20 \mathrm{mV}$ (Kaila, 1994). Thus, the driving force (DF), which is the difference between the membrane potential and the equilibrium potential $\left(\mathrm{DF}=\mathrm{V}_{\mathrm{m}}-\mathrm{E}_{\mathrm{ion}}\right)$, is greater for $\mathrm{HCO}_{3}{ }^{-}$than it is for $\mathrm{Cl}^{-}$when the neuron is at rest.
The reversal potential of GABA is the membrane potential at which there is no net current upon receptor activation and is a combination of $\mathrm{E}_{\mathrm{Cl}}$ and $\mathrm{E}_{\mathrm{HCO} 3}$. $\mathrm{E}_{\mathrm{GABA}}$ can be calculated from the Goldman-Hodgkin-Katz equation, which requires knowledge of the intra- and extracellular concentrations of $\mathrm{Cl}^{-}$and $\mathrm{HCO}_{3}{ }^{-}$ and their conductances. Because $\mathrm{GABA}_{\mathrm{A}} \mathrm{Rs}$ are significantly more permeable to $\mathrm{Cl}^{-}$than $\mathrm{HCO}_{3}{ }^{-}$(Kaila et al., 1989; FatimaShad and Barry, 1993), $\mathrm{E}_{\mathrm{GABA}}$ sits much closer to $\mathrm{E}_{\mathrm{Cl}}$ than to $\mathrm{E}_{\mathrm{HCO} 3}$, and thus $\mathrm{E}_{\mathrm{GABA}}$ is often taken as $\mathrm{E}_{\mathrm{Cl}}\left(\mathrm{E}_{\mathrm{GABA}} \approx \mathrm{E}_{\mathrm{Cl}}\right)$.

Gamma-amino butyric acidergic transmission is plastic and can undergo short- and long-term shifts in the $\mathrm{Cl}^{-}$and $\mathrm{HCO}_{3}{ }^{-}$gradients in postsynaptic neurons (Rivera et al., 2005; Lamsa et al., 2010; Raimondo et al., 2012). Shortterm GABAergic plasticity can be induced by high-frequency GABAergic stimulation, which dissipates the driving force for $\mathrm{Cl}^{-}$and reduces the efficacy of fast GABAergic inhibition (Thompson and Gähwiler, 1989; Doyon et al., 2011, 2016). This phenomenon was described more than two decades ago, as the amplitudes of $\mathrm{GABA}_{\mathrm{A}} \mathrm{R}$-mediated inhibitory postsynaptic currents (IPSCs) were aptly described as "fading" currents (Huguenard and Alger, 1986). This demonstrates that repetitive stimulation results in weakened inhibition (disinhibition) in an activity-dependent manner, which can be due to progressive depletion of the $\mathrm{Cl}^{-}$driving force (referred to as ionic plasticity) and/or the sensitization of $\mathrm{GABA}_{\mathrm{A}} \mathrm{Rs}$ (Rivera et al., 2005; Raimondo et al., 2012). Bearing this in mind, it's unsurprising that feedback inhibition such as in the BG might be more susceptible to activity-dependent disinhibition which we discuss below, although this has not been experimentally demonstrated in HD.

Long-term GABAergic ionic plasticity depends upon changes in membrane expression and transport activity of KCC2 and NKCC1, as well as carbonic anhydrase isoform VII (CAVII), which regulates intracellular $\mathrm{pH}$ and consequently $\mathrm{E}_{\mathrm{HCO} 3}$ (Kaila and Voipio, 1987; Ruusuvuori et al., 2004; Rivera et al., 2005). Repetitive pre-and postsynaptic activity of hippocampal neurons decreases the strength of inhibition, due to a depolarization of $\mathrm{E}_{\mathrm{GABA}}$, which results from a reduction in $\mathrm{KCC} 2$-mediated $\mathrm{Cl}^{-}$ -extrusion (Woodin et al., 2003). It is important to note that depolarizing GABA does not necessarily result in excitation as depolarizing GABA can dampen the excitatory response in target cells via shunting inhibition. Shunting inhibition via $\mathrm{GABA}_{\mathrm{A}} \mathrm{R}$ activation leads to a decreased membrane resistance, which effectively increases the background conductance consequently, spatially and temporally dampening the excitatory signal (Doyon et al., 2016).

\section{Cation-Chloride Cotransporters Overview}

As GABA signaling depletes the $\mathrm{Cl}^{-}$driving force, CCCs are key players in maintaining the efficacy of synaptic inhibition. The role of CCCs was first discovered in the 1970s, when researchers discovered that erythrocytes could recover their volume upon hypertonic shrinkage through a $\mathrm{Na}^{+}-\mathrm{K}^{+}$ cotransport mechanism that was sensitive to furosemide, a CCC blocker (Kregenow, 1981). Two decades later, the $\mathrm{Na}^{+}-\mathrm{K}^{+}$ cotransport was determined to be mediated by the "electrically silent" $\mathrm{Na}-\mathrm{K}-2 \mathrm{Cl}$ cotransport mechanisms of $\mathrm{NKCC1}$ and 


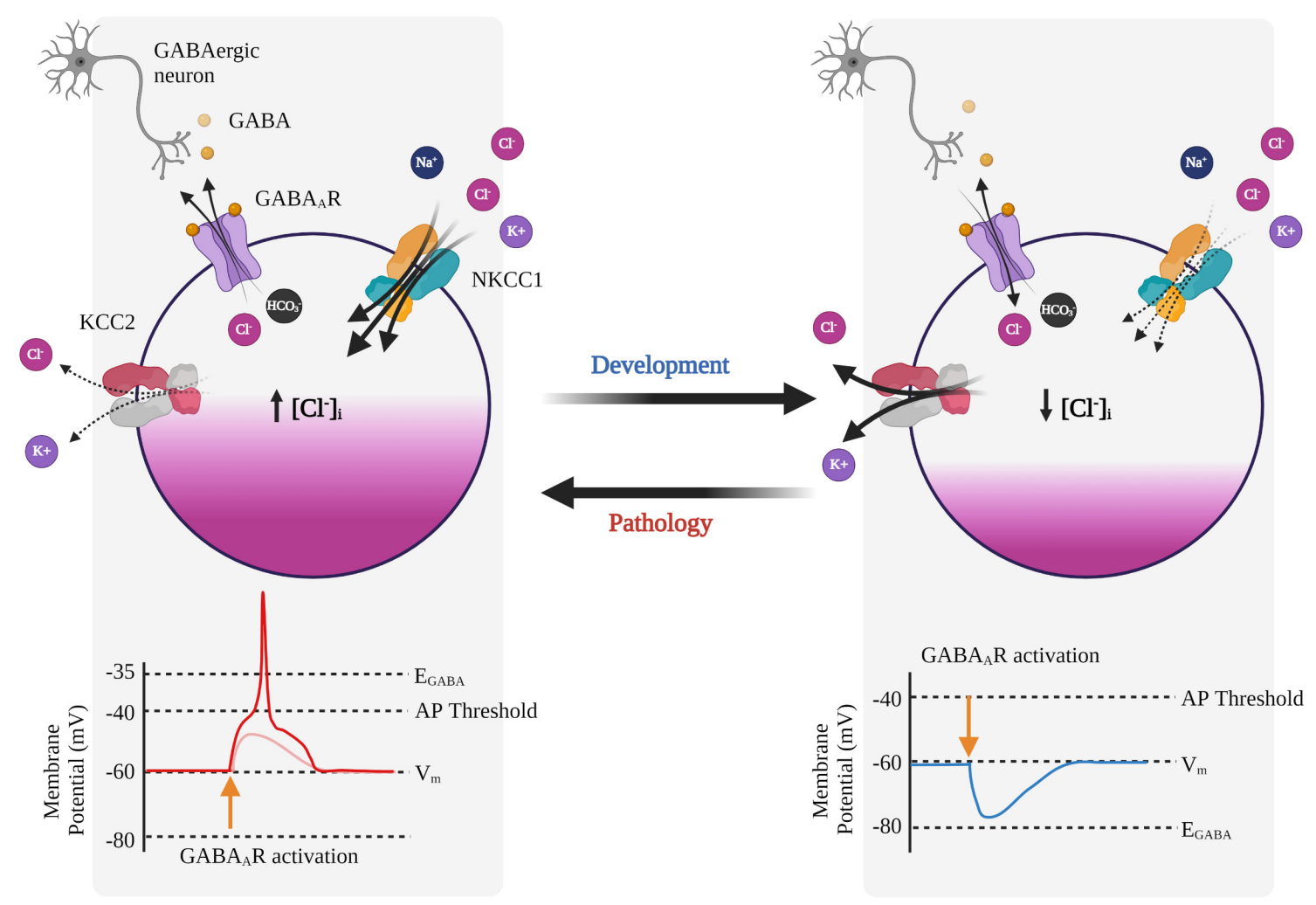

FIGURE 2 | Neuronal $\mathrm{Cl}^{-}$regulation and its effects on $\mathrm{GABA}_{A}$ receptor signaling during development and pathology. GABA receptor (GABA $\mathrm{R}$ ) signaling is developmentally regulated and switches from depolarizing to hyperpolarizing. In immature neurons, the GABA response is depolarizing due to relatively higher expression of NKCC1 compared to KCC2, resulting in $\mathrm{Cl}^{-}$efflux upon $\mathrm{GABA}_{A} \mathrm{R}$ activation, and subsequent depolarization of the membrane potential. In mature neurons, expression of KCC2 increases leading to $\mathrm{Cl}^{-}$influx upon GABAA activation and a hyperpolarizing response of GABA. In some pathologies, KCC2 activity is reduced and can promote reversion back to a phenotypically immature state and a depolarizing response of GABA, which can also lead to GABA-mediated excitation. Created with BioRender.com.

NKCC2 (Hebert and Gamba, 1994). CCCs form the SLC12 transporter family, which facilitate electroneutral transport of $\mathrm{Cl}^{-}$by coupling energetically-favorable transport of $\mathrm{Na}^{+}$and/or $\mathrm{K}^{+}$across the plasma membrane to regulate osmolarity and water balance (Arroyo et al., 2013). CCCs are divided into two groups: $\mathrm{Na}^{+}$-dependent transporters such as NKCC1, NKCC2, and NCC, while the $\mathrm{Na}^{+}$-independent branch includes KCC1, KCC2, KCC3, and KCC4. Two other members of the SLC transporter family are CCC9 and CIP, whose function still remain unclear (Blaesse et al., 2009; Arroyo et al., 2013). Despite the fact that CCCs were cloned more than two decades ago, their protein structures remained largely unknown until fairly recently with the development of more sensitive methods to uncover CCC structure with higher resolution, particularly through cryogenic electron microscopy (cryo-EM) and single-particle imaging (Chew et al., 2019; Liu et al., 2019b; Yang et al., 2020; Zhang et al., 2021). These studies uncovered two $\mathrm{Cl}^{-}$binding sites specifically in human KCC1 and KCC4, with one involved in ion transport while the other appears to play a more facilitative role in ensuring the former is occupied via allosteric interactions (Liu et al., 2019b). Interestingly, the $N$-terminal loop performs an auto-inhibitory function which blocks cytoplasmic entry of the translocation pore (Chi et al., 2021). Indeed, improved resolution of CCC tertiary structures will likely facilitate the much-needed uncovering of CCC-interacting peptides or regulatory molecules as potential therapeutic strategies.

\section{$\mathrm{K}^{+}-\mathrm{Cl}^{-}$Co-transporter-2 Expression and Function}

KCC2 is encoded by the SLC12A5 gene (Sallinen et al., 2001) and unlike the other CCCs, KCC2 is constitutively active, operating under isotonic conditions due to the presence of a 15-residue C-terminal domain (Mercado et al., 2006). KCC2 is largely neuron-specific (Williams et al., 1999) and is known for its role in maintaining $\mathrm{Cl}^{-}$homeostasis in adult neurons by extruding $\mathrm{Cl}^{-}$against its concentration gradient driven by the energetically favorable extrusion of $\mathrm{K}^{+}$(Gamba, 2005; Chamma et al., 2012). KCC2 dysfunction leads to increased intracellular $\mathrm{Cl}^{-}$and reversion to a developmentally immature state with depolarizing GABA and increased neuronal excitability (Figure 2; BenAri et al., 2012a). KCC2 is also considered a moonlighting protein, with roles outside of ion transport which include cell migration, dendritic formation, spine morphology and synaptogenesis mediated through interactions with the dendritic cytoskeleton (Kaila et al., 2014; Blaesse and Schmidt, 2015). The 
cytosolic C-terminal tail of KCC2 interacts directly with the cytoskeletal protein $4.1 \mathrm{~N}$ to provide dendritic structural support (Li et al., 2007). Without KCC2, dendritic spine morphology is compromised, producing stubby structures that compromise the function of excitatory synapses (Li et al., 2007). Indeed, with the broad functions (independent of ion transport) of KCC2, it's no surprise that reduced GABAergic inhibition is not the only phenotype in KCC2-related pathologies and may contribute to other symptoms in HD (Tang, 2020; Virtanen et al., 2021).

During development GABA transmission is depolarizing, which is thought to provide the main source of excitatory drive during activity-dependent formation of neuronal networks (Ben-Ari et al., 1989). However, the developmental switch in GABA polarity remains controversial (Ben-Ari et al., 2012b; Bregestovski and Bernard, 2012; Zilberter, 2016) due to discrepancies between GABA actions in vitro (Ben-Ari et al., 1989, 2007) and in vivo (Valeeva et al., 2016). The switch in the GABA-mediated response is determined by the relative surface membrane expression of KCC2 and NKCC1, although the pattern of expression seen throughout development is neuron-type and species-specific (Rivera et al., 1999; Li et al., 2002). At approximately postnatal day 15 (P15), KCC2 mRNA increases, exceeding levels of NKCC1 mRNA, leading to GABA's hyperpolarizing response in the cortex and hippocampus of rats (Wang et al., 2002). At around P21, KCC2 protein expression stabilizes and reaches mature levels (Takayama and Inoue, 2007), reducing intracellular $\mathrm{Cl}^{-}$and producing a hyperpolarizing shift in $\mathrm{E}_{\mathrm{GABA}}$ (Mueller et al., 1984). The upregulation of KCC2 transcripts is regulated by various neurotrophic factors (Watanabe and Fukuda, 2015), such as BDNF and its receptor tropomyosin-related kinase B (TrkB) (Ludwig et al., 2011). Interestingly, BDNF-TrkB signaling in mature neurons produces the opposite effects, leading to the downregulation of KCC2 (Rivera et al., 2002). Given the severely altered levels of BDNF in $\mathrm{HD}$ and BDNF's role in regulating KCC2 transcripts, we hypothesize that there may be a causal relationship between the reduction in $\mathrm{BDNF}$ and $\mathrm{KCC} 2$ dysfunction in $\mathrm{HD}$, though the mechanisms underlying this alteration requires further investigation.

$\mathrm{K}^{+}{ }_{-} \mathrm{Cl}^{-}$co-transporter-2 expression is largely mediated through membrane trafficking and stability in the plasma membrane, a process mainly regulated by (de)phosphorylation (Russell, 2000; Rinehart et al., 2009; Kahle et al., 2013). An important regulatory phosphorylation site is serine 940 (S940), a target of protein kinase C (PKC) (Lee et al., 2007). PKCmediated phosphorylation of $\mathrm{S} 940$ increases stability in the plasma membrane by reducing lysosome-dependent cleavage and the rate of internalization from the membrane. In contrast, NMDA receptor-mediated de-phosphorylation of S940 via protein phosphatase 1 (PP1) reduces KCC2 activity by the rate of KCC2 internalization at the plasma membrane (Lee et al., 2011). Reduction of KCC2 expression can also occur through the calcium-activated protease calpain, which is mediated by MAPK phosphorylation (Puskarjov et al., 2012). KCC2 phospho-regulation can also occur through two other threonine residues, T906 and T1007. These residues are phosphorylated by the With no lysine kinase (WNK)-regulated Ste20-related proline/alanine-rich kinase (SPAK)/Oxidative stress response 1 (OSR1) kinases. Activation of the WNK-SPAK/OSR1 pathway leads to increased intracellular $\mathrm{Cl}^{-}$by inhibiting KCC2 and increasing NKCC1 activity (Rinehart et al., 2009; Gagnon and Delpire, 2012; de Los Heros et al., 2014). Given that activation of the WNK-SPAK/OSR1 pathway produces antagonistic effects on KCC2 and NKCC1, it remains to be determined whether the phosphorylation status of either KCC2 and/or NKCC1 are impacted in HD.

\section{$\mathrm{Na}^{+}-\mathrm{K}^{+}-\mathrm{Cl}^{-}$Co-transporter-1}

$\mathrm{Na}^{+}-\mathrm{K}^{+}-\mathrm{Cl}^{-}$co-transporter-1 is encoded by the SLC12A2 gene and produces antagonistic effects to KCC2. NKCC1 mediates cellular $\mathrm{Cl}^{-}$influx which is driven by the highly favorable $\mathrm{Na}^{+}$ inward direction. In addition to expression in the CNS, NKCC1 is broadly expressed such as in the salivary gland, sweat gland, lungs, and intestine (Delpire and Gagnon, 2018; Koumangoye et al., 2021), which can lead to unwanted side effects in NKCC1 drug targeting. NKCC1 activity is regulated by the WNK-SPAK kinase pathway, whereby phosphorylation by SPAK and OSR1 on the $N$-terminal activates transporter activity (Gagnon et al., 2007). Due to the high degree of flexibility, the tertiary structure and $N$-terminal domain of NKCC1 had been difficult to elucidate until recently (Chew et al., 2019). NKCC1 is sensitive to loop diuretic drugs such as furosemide and bumetanide used to lower blood pressure and a therapy for cardiovascular diseases (Chobanian et al., 2003).

\section{$\mathrm{K}^{+}-\mathrm{Cl}^{-}$CO-TRANSPORTER-2 AND $\mathrm{Na}^{+}-\mathrm{K}^{+}-\mathrm{Cl}^{-}$CO-TRANSPORTER-1 AND CHLORIDE DYSREGULATION IN NEURODEGENERATIVE AND NEURODEVELOPMENTAL DISORDERS}

\section{Overview}

Alterations in CCC expression occur in both neurodegenerative and neurodevelopmental disorders. Most commonly, in neuronal hyperexcitability, which in turn, promotes epileptic seizures (Kahle et al., 2008; Moore et al., 2017). Moreover, reduction of pathological increases in intracellular $\mathrm{Cl}^{-}$used to restore GABAergic inhibition have proven to reduce seizure severity (Dzhala et al., 2008; Mazarati et al., 2009). CCC targeting has been particularly effective in clinical trials with bumetanide used to reduce intracellular $\mathrm{Cl}^{-}$in autism spectrum disorders (ASDs) (Ben-Ari, 2017) such as in Rett syndrome (RTT), a disorder caused by a mutation in the transcriptional repressor Methyl CpG binding protein 2 (MeCP2) gene (Chahrour et al., 2008). In RTT, GABAergic inhibition is impaired due to reduced KCC2 function which can be rescued by overexpressing KCC2 in MeCP2-deficient neurons (Tang et al., 2016) or using KCC2 expression-enhancing compounds (KEECs) (Tang et al., 2019). Similarly, KCC2 downregulation following neuropathic pain has been well studied (Hasbargen et al., 2010; Kahle et al., 2014; Chen et al., 2018). Neuropathic pain leads to disinhibition in the spinal cord dorsal horn, which could be rescued by enhancing 
$\mathrm{Cl}^{-}$extrusion by KCC2 in rodent models (Kahle et al., 2014; Chen et al., 2018). But what about the involvement of KCC2 and NKCC1 in neurodegenerative diseases? Below we outline the recently reported experimental evidence of CCC dysfunction in neurodegenerative diseases, such as HD.

\section{$\mathrm{K}^{+}-\mathrm{Cl}^{-}$Co-transporter-2 and $\mathrm{Na}^{+}-\mathrm{K}^{+}-\mathrm{Cl}^{-} \mathrm{Co}$-transporter-1 and Chloride Dysregulation in the Huntington's Disease Brain}

The link between altered CCC transcripts in HD was first identified in an unbiased interactome study of the unfolded protein response (UPR) in HD (Kalathur et al., 2015). To elucidate the mechanisms underlying cell apoptosis, Kalathur et al. (2015) examined the UPR, which is activated by accumulated misfolded protein in the endoplasmic reticulum (Kalathur et al., 2015). The authors examined UPR gene expression, and discovered that SLC12A5 (KCC2) was downregulated and SLC12A2 (NKCC1) was upregulated. Moreover, proteomic analysis of $\mathrm{Htt}$-interacting proteins ranked SLC12A5 as one of the topmost Htt-correlated module containing Htt itself (Shirasaki et al., 2012).

Based on these powerful unbiased Htt-interactomes, the importance of GABAergic inhibition in learning and memory, and the known deficits in hippocampal-dependent memory in HD, Dargaei et al. (2018) aimed to characterize CCC function in the HD hippocampus (Dargaei et al., 2018). This was the first study to demonstrate impaired CCC function in HD leading to GABA-mediated excitation. Despite the various interactome studies linking Htt and KCC2 (Shirasaki et al., 2012; Kalathur et al., 2015; Mahadevan et al., 2017), the authors were the first to validate the interaction between KCC2 and Htt protein in a HD mouse model; they performed co-immunoprecipitation assays in the R6/2 model. R6/2 is a transgenic fragment model of $\mathrm{HD}$ that overexpresses exon 1 of the human HTT with $\sim 120-150$ CAG repeats (Mangiarini et al., 1996) and although it represents the juvenile form of $\mathrm{HD}$, it is the most well studied mouse model owing to early development of symptoms (Carter et al., 1999). To ensure that CCC alterations were consistent across multiple mouse models, they used another transgenic mouse model which expresses the full-length HTT with 128 repeats with a yeast artificial chromosome (YAC), called the YAC128 (Hodgson et al., 1999). Unlike the R6/2, the YAC128 display a slower progression of the disease and because of this late-onset, are considered to be one of the most clinically relevant mouse models of HD (Menalled and Chesselet, 2002). The authors demonstrated that in $\mathrm{HD}$, hippocampal neurons reverted to an immature state, with increased NKCC1 expression and reduced KCC2 expression, which may underlie cognitive deficits in HD. Interestingly, increased NKCC1 appeared to occlude the effects of KCC2 reduction, suggesting that the reversal of GABA polarity was primarily due to increased NKCC1 rather than decreased KCC2 function. This finding is interesting, considering that Htt and KCC2 interact, and there is currently no evidence of any interaction between $\mathrm{Htt}$ and NKCC1. To conclude, the authors showed that daily intraperitoneal (IP) injections of the
FDA-approved NKCC1 inhibitor, bumetanide, was sufficient to restore hippocampal-dependent memory in R6/2 mice. To confirm that the memory improvements were not due to offtarget effects (Savardi et al., 2021), the authors used stereotaxic implantation of a micro-osmotic pump to deliver bumetanide to the brain, and found that this route of administration also restored cognitive deficits in R6/2 mice. Although bumetanide has proven to mitigate cognitive defects in the presymptomatic phase of HD, most patients are diagnosed with $\mathrm{HD}$ only after the onset of motor deficits and thus the HD-associated cognitive impairments produces a significant burden on caregivers and families (Domaradzki, 2015). Therefore, with the development of more sensitive methods for early diagnosis and the welldefined pattern of inheritance, treating premanifest HD patients by targeting CCCs appears to be a promising therapeutic strategy.

An obvious question is whether depolarizing GABA underlies motor deficits classically associated with HD. To address this, Hsu et al. (2019) demonstrated that NKCC1 transcripts and protein expression were higher in the striatum of the R6/2 and Hdh150q/7q mouse models and in the caudate nucleus of HD patients (Hsu et al., 2019). The authors demonstrated that the impairments in $\mathrm{E}_{\mathrm{GABA}}$ progressively depolarized from $\sim-60 \mathrm{mV}$ to $\sim-40 \mathrm{mV}$ in 10 -week-old to 16 -week-old R6/2 mice, respectively. Of note, the authors did not discriminate between D1- and D2-MSNs in the striatum and since D2-MSNs are known to demonstrate synaptic dysfunction earlier, it is possible that the progressive depolarization in $\mathrm{E}_{\mathrm{GABA}}$ was a result of the differential degeneration between the two pathways. In contrast to Dargaei et al. (2018), the authors attributed the aberrant CCC expression to neuroinflammation. The researchers rescued motor deficits by using an shRNA against NKCC1 in the striatum of R6/2 mice (shNKCC1) and that the expression of mHTT in astrocytes alone was sufficient to upregulate NKCC1. Determining whether the decrease in KCC2 expression happen before the increase in NKCC1 expression is important, as this will reveal prioritization for CCC-based therapeutic interventions.

In view of CCC dysfunction in $\mathrm{HD}$ and its importance for the maintenance of synaptic inhibition, we now discuss $\mathrm{Cl}^{-}$ regulation via CCCs in the basal ganglia, the primary site of histopathological damage in HD (Albin, 1995).

\section{CHLORIDE DYNAMICS AND GAMMA-AMINO BUTYRIC ACID SIGNALING IN THE BASAL GANGLIA}

\section{Overview}

As explained above, chorea presents in earlier stages of the disease, while late stages are characterized by progressive hypokinesia and bradykinesia (Huntington, 1872). These biphasic changes throughout disease progression are caused by differential susceptibility in the direct and indirect pathways of BG circuitry. We first provide a brief overview of the BG, before delving into GABAergic signaling in this group of highly interconnected subcortical nuclei. The BG is primarily associated with motor control, including motor learning and fine-tuning 
motor behavior, and various non-motor behaviors, including emotional regulation, decision making and learning and memory (Graybiel et al., 1994; Graybiel and Grafton, 2015). Structures within the BG include the striatum, the Nucleus accumbens (NAcc), the internal (GPi) and external segments of the globus pallidus (GPe), the subthalamic nucleus (STN), substantia nigra pars reticulata $(\mathrm{SNr})$ and substantia nigra pars compacta $(\mathrm{SNc})$ (Alexander and Crutcher, 1990; Hedreen and DeLong, 1991). Input structures such as the striatum, NAcc, and STN, receive efferents from cortical, thalamic and nigral regions forming the beginnings of the direct, indirect and hyper-direct pathways (Lanciego et al., 2012). These input structures send their outputs to the intrinsic nuclei within the BG which include the GPe, STN and $\mathrm{SNc}$, which then relay BG information between the input and output structures. Output structures include the GPi and the $\mathrm{SNr}$, which receive information from other BG output nuclei and send projections to the ventral nuclei of the thalamus, which then sends $B G$ information back to the cerebral cortex to form the cortico-BG-thalamocortical (CBGTC) loop (Alexander et al., 1986; Albin et al., 1989). Recently, as part of a consortium to fully explore the primary motor cortex, Foster et al. (2021) examined the CBGTC loop to map multi-synaptic output pathways of striatal domains (Foster et al., 2021), and determined that the direct pathway had greater convergence of striatal inputs than the indirect pathway, suggesting greater specificity of the indirect pathway. This decreased degree of informational convergence in the GPe could provide some insight on the susceptibility of the indirect pathway in $\mathrm{HD}$.

\section{Chloride Dynamics and Gamma-Amino Butyric Acid Signaling in the Direct and Indirect Pathways}

A recent study examined the effects of $\mathrm{Cl}^{-}$dynamics on $\mathrm{SNr}$ responses to GABAergic pallidal and striatal inputs (activation via indirect and direct pathway, respectively) to ultimately make predictions about its impact on behavior (Phillips et al., 2020). $\mathrm{SNr}$ responses to GABAergic inputs from the direct and indirect pathway were determined to be diverse, with excitatory effects attributed to intracellular $\mathrm{Cl}^{-}$handling. Stimulation of GPe and striatal projections resulted in biphasic inhibitory-to-excitatory responses in $\mathrm{SNr}$ neurons that were mediated by rapid $\mathrm{Cl}^{-}$ accumulation, which can overwhelm $\mathrm{Cl}^{-}$extrusion via KCC2. Using optogenetic simulation, the researchers discovered that activation of soma-projecting GPe-neurons led to a greater proportion of excitatory responses in $\mathrm{SNr}$-neurons, compared to dendritic-projecting striatal neurons, which suggests that the $\mathrm{E}_{\mathrm{GABA}}$ in the soma is more depolarized than in the dendrites. This is somewhat surprising given that the difference in volume between the soma and dendrites (which affect the rates of $\mathrm{Cl}^{-}$ accumulation), predicts that the limited volume in dendrites should undergo faster rates of $\mathrm{Cl}^{-}$accumulation, and therefore exhibit a more depolarized $\mathrm{E}_{\mathrm{GABA}}$ (Doyon et al., 2016). However, this difference in $\mathrm{E}_{\mathrm{GABA}}$ can be attributed to increased firing rate of GPe neurons compared to striatal neurons and/or the preferential localization of KCC2 in the dendrites of GABAergic $\mathrm{SNr}$ neurons compared to the soma (Gulácsi et al., 2003).
Considering this work, it appears that high GPe GABAergic output can lead to increased $\mathrm{Cl}^{-}$loading in the soma of $\mathrm{SNr}$ neurons, which can lead to greater/faster collapse of the $\mathrm{Cl}^{-}$gradient through indirect pathway activation, consequently leading to excitatory GPe control of the SNr. This change in GABA polarity also compromises the ability of striatal neurons (mainly D1-MSNs of the direct pathway) to inhibit $\mathrm{SNr}$ dendrites, which may result in slow response times or even no response in perceptual decision-making tasks (Phillips et al., 2020). Interestingly, tonically spiking dopaminergic neurons in the $\mathrm{SNr}$ do not express KCC2, though it has been postulated that the weak GABAergic inhibitory drive is necessary for tonic release of dopamine (Gulácsi et al., 2003).

As D2-MSNs degenerate earlier in the disease, striatal connectivity to the GPe is lost, leading to overactivation of GPe neurons, which is believed to underlie chorea (Figure 3; Crossman, 1987; Reiner et al., 1988). In human HD patients, deep brain stimulation of the GPe has proven beneficial in treating motor and cognitive dysfunction, although the mechanisms underlying this dysfunction remains unclear (Da Cunha et al., 2015; Wojtecki et al., 2016). However, in R6/2 mice, GPe neurons have proven to be hyperexcitable and blockade of $\mathrm{GABA}_{\mathrm{A}} \mathrm{Rs}$ facilitated bursting activity (Akopian et al., 2016). Though the mechanisms leading to bursting are not fully understood, this finding leads us to hypothesize that KCC2 and/or $\mathrm{Cl}^{-}$ homeostasis is impaired in the GPe and/or other BG nuclei. Based on the predictions of this model, and if our hypothesis is correct (i.e., $\mathrm{Cl}^{-}$handling is impaired in the GPe and/or other BG structures), the consequences can be far-reaching. With reduced KCC2 function and GPe hyperexcitability in HD, this could create a potentially deleterious loop within the BG circuitry, changing GABA polarity, particularly along the indirect pathway. Intuitively, with enhanced excitability, increasing inhibition appears to be the most logical answer. But as we consider GABA actions in the $\mathrm{BG}$ and the dynamic nature of $\mathrm{Cl}^{-}$regulation, it becomes clear why enhancing GABAergic conductance can worsen neuronal dysfunction rather than temper it.

\section{Activity-Dependent Disinhibition Due to $\mathrm{Cl}^{-}$Accumulation in the BG}

An important factor in determining the susceptibility to activitydependent disinhibition is the underlying neural network topology (Doyon et al., 2011, 2016). To illustrate this point, one can imagine a simple reciprocal connection between two neurons that form a small feedback loop; whereby an inhibitory neuron provides negative feedback to a neuron from which it receives excitatory input. Reduced KCC2 function (or increased NKCC1) in the excitatory neuron would lead to impaired inhibition, and therefore would increase its firing rate. Increased firing would consequently lead to enhanced excitatory input onto the inhibitory neuron. As the inhibitory neuron experiences increased excitation, it would then increase inhibitory feedback onto the excitatory neuron, which would further enhance the $\mathrm{Cl}^{-}$ load in the excitatory neuron (Figure 4). This scenario provides insight as to why some networks, such as the BG, might be more vulnerable to activity-dependent disinhibition than others. 

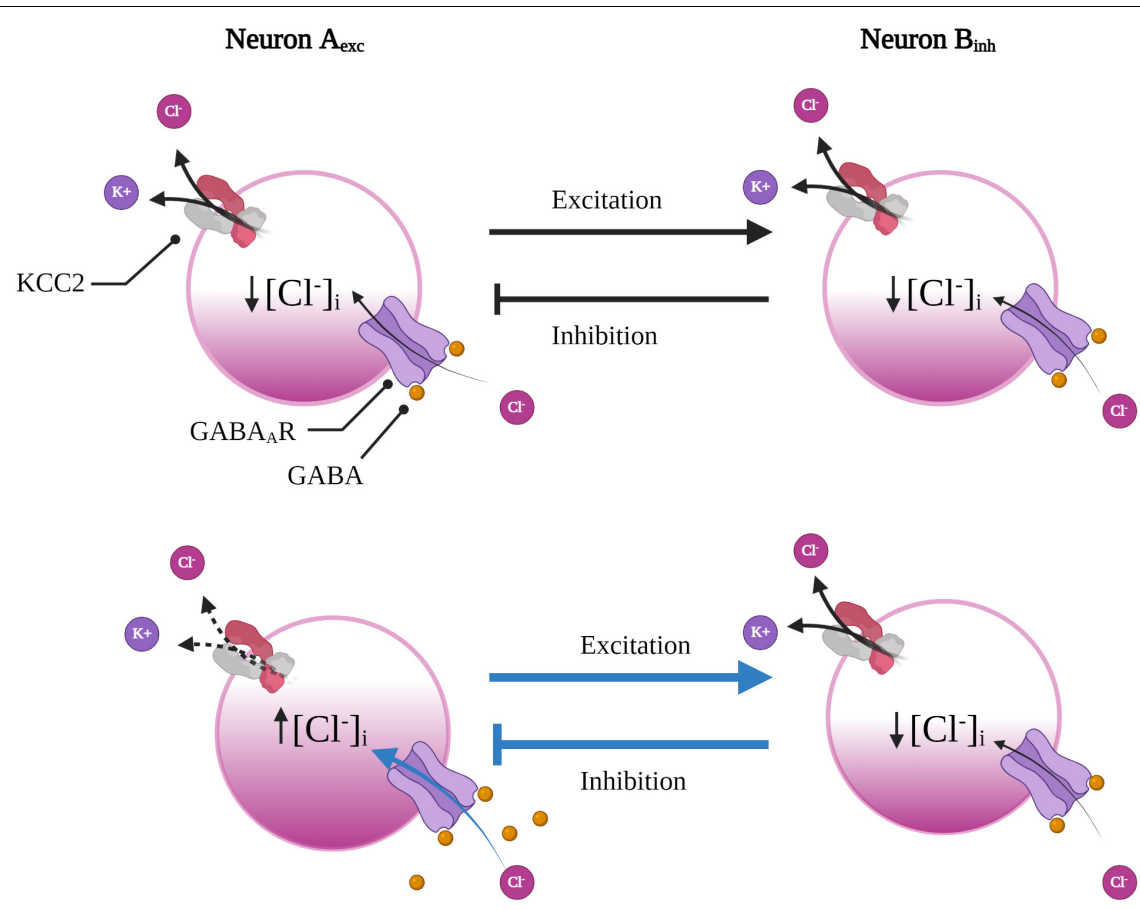

FIGURE 3 | Underlying network connection can render some neurons more susceptible to GABAergic disinhibition. Excitatory neuron A is reciprocally connected with inhibitory neuron B to form a small feedback loop. With a reduction in KCC2 function (or increase in NKCC1, not shown here), in excitatory neuron A (below), $\mathrm{Cl}^{-}$will accumulate leading to a faster rate of collapse in the $\mathrm{Cl}^{-}$driving force subsequently weakening GABAergic inhibition. As neuron $\mathrm{A}$ experiences less inhibition, it will fire more, leading to greater excitation of the inhibitory neuron B. As a result of increased excitatory input, the inhibitory neuron will then increase inhibitory input back onto the excitatory neuron A, which will further enhance the $\mathrm{Cl}^{-}$load in the excitatory neuron to create a deleterious loop. Created with BioRender.com.

As inhibition is required for fine-tuning gain and modulating oscillatory activity within neural networks (Doyon et al., 2016), a mild reduction in KCC2 function in one component might lead to catastrophic failure of feedback loops embedded in inhibitory networks. For example, abnormal oscillatory activity in the BG circuitry was hypothesized to underlie resting tremor in Parkinson's disease (PD) (Plotkin and Goldberg, 2019). The theory that tremors were caused by altered rhythmogenesis within the CBGTC loop was due to the discovery that the STN and GPe were autonomous pacemakers that gave rise to spontaneous oscillatory activity (Plenz and Kital, 1999). The STN and GPe are reciprocally connected, forming a small subcircuit much like the scenario described above (Figure 3), where GPe neurons inhibits STN neurons, which also provides excitatory feedback to the GPe. Based on the predictions of our hypothetical scenario (Figure 3) and the known HDassociated dysfunction in the GPe and STN, one can imagine what might happen if the $\mathrm{Cl}^{-}$regulation is overwhelmed in the GPe and/or the STN due to reduced KCC2 function. Indeed, the results become more consequential when considering that a portion of GPe neurons project back to the striatum, forming another (disinhibitory) feedback loop (Abdi et al., 2015). Due to the presence of these reciprocal and convergent connections, which form multiple closed-feedback loops, it seems impossible to pinpoint accurately where and when synaptic dysfunction might originate. Any structure within the indirect pathway might experience increased synaptic delays in negative-feedback due to dysregulated gain, leading to destabilization of the CBGTC loop (Plotkin and Goldberg, 2019). Based on the underlying network topology and the computational modeling in predicting the effects of dysregulated $\mathrm{Cl}^{-}$in the $\mathrm{BG}$, it is tempting to speculate whether this might play a role in the enhanced susceptibility of the indirect pathway due to impaired $\mathrm{Cl}^{-}$handling.

\section{CHLORIDE DYNAMICS AND GAMMA-AMINO BUTYRIC ACID SIGNALING IN THE HEALTHY AND HUNTINGTON'S DISEASE STRIATUM}

\section{Overview}

In $\mathrm{HD}$, striatal degeneration is highly systematic and undergoes extensive neuronal loss of MSNs while striatal interneurons are relatively spared (Vonsattel and DiFiglia, 1998). Although the preferential neurodegeneration of MSNs has been extensively studied in HD, the mechanisms remain unclear. MSN exhibiting low spontaneous activity (Plenz and Kitai, 1998), which may be due to strong feedforward inhibition from surrounding parvalbumin-positive $(\mathrm{PV}+)$ interneurons and/or intrinsic membrane properties that make it difficult for MSNs fire (Tepper and Plenz, 2004; Burke et al., 2017). For instance, MSNs are characterized by their hyperpolarized resting membrane 


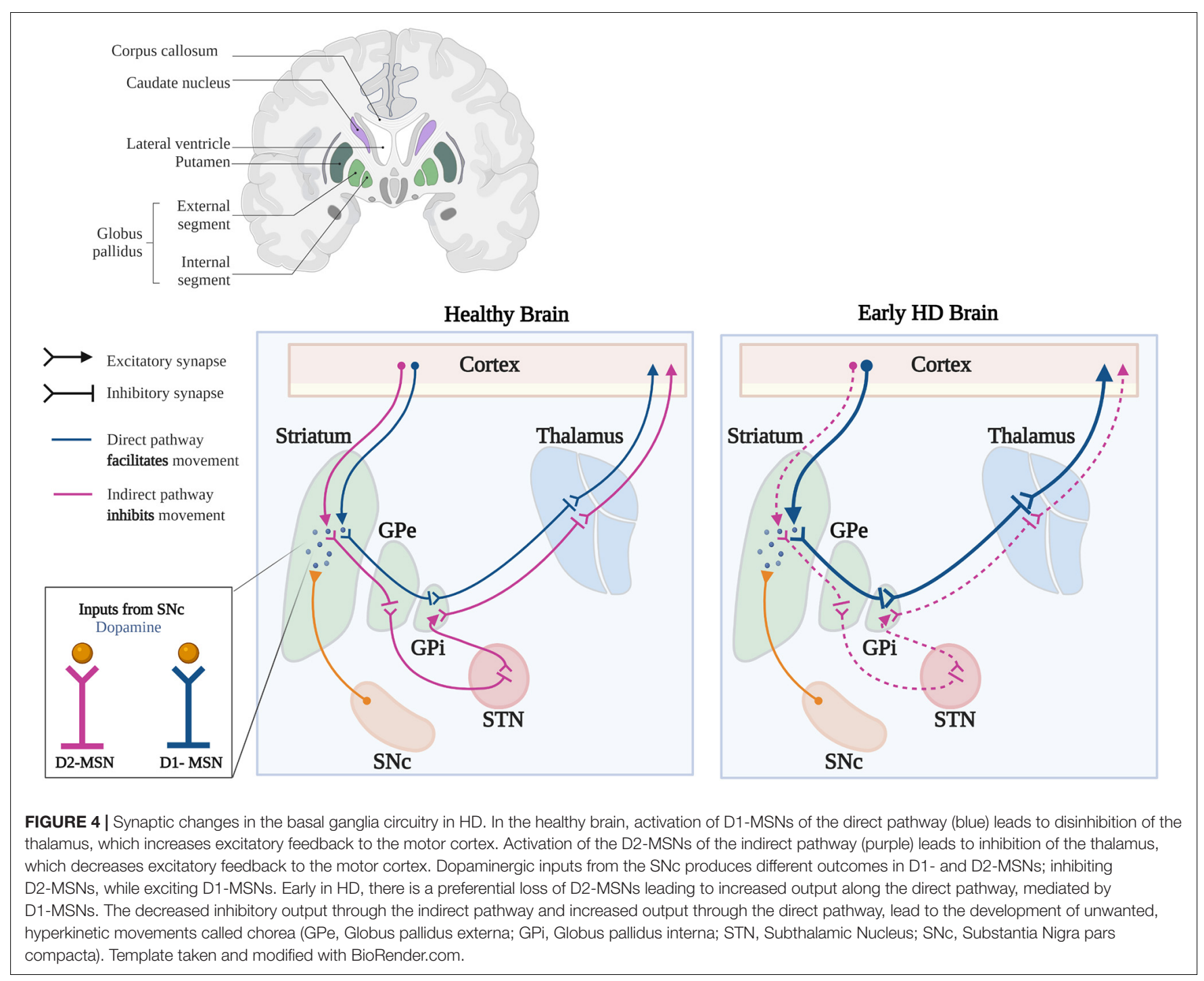

potential $(\sim 80$ to $-85 \mathrm{mV})$ and low membrane resistance (Wilson and Kawaguchi, 1996). This hyperpolarized membrane potential is one of two preferred MSN states - the "down" and "up" states. In the down state, MSNs rarely fire, in contrast to its presence in the up state $(\sim-50 \mathrm{mV})$, which sits closer to action potential threshold $(-40$ to $-35 \mathrm{mV})$ and requires strong convergent glutamatergic input and possibly depolarizing GABAergic signaling (Plenz, 2003). With low firing rates and a hyperpolarized resting membrane potential, it appears that MSNs evolved to convey excitatory information with high signal to noise ratio, allowing only entry of relevant signals into the striatum.

Understanding GABA signaling in the striatum and the functional differences of D1- and D2-MSNs provides some insight into the enhanced susceptibility of D2-MSNs in HD, although despite the wealth of knowledge surrounding the two MSN subtypes, this has proven to be a difficult task, which we highlight below.

\section{Chloride Dynamics and Gamma-Amino Butyric Acid Signaling in the Healthy Striatum}

Earlier studies of MSN-MSN monosynaptic transmission demonstrated that GABA is depolarizing at rest ( $\mathrm{E}_{\mathrm{GABA}} \sim 60 \mathrm{mV}$; $\mathrm{V}_{\mathrm{m}} \sim 85 \mathrm{mV}$ ) (Wilson and Kawaguchi, 1996; Plenz, 2003), which is thought to facilitate transition into the upstate (Plenz, 2003). Notably, depolarizing GABA could act to dampen shunting effects of rectifying $\mathrm{K}^{+}$channels on cortical glutamatergic transmission at rest (Wilson, 1992; Plenz, 2003). In addition, the effects of GABA change at more depolarized membrane potentials close to spiking threshold, where GABA can effectively delay action potential firing (Koós and Tepper, 1999). This temporal modulation of GABA on MSN firing could impact spike timing necessary for cortico-striatal plasticity and network activity (Plenz, 2003). As GABAergic signaling in MSNs appears to act through shunting inhibition (as opposed to hyperpolarizing inhibition), it's important to note that this also 
relies on the $\mathrm{Cl}^{-}$gradient and is susceptible to breakdown via $\mathrm{Cl}^{-}$accumulation. Without restoration of the $\mathrm{Cl}^{-}$driving force, shunting inhibition becomes ineffective, especially when modulating repetitive spiking. Although $\mathrm{Cl}^{-}$flux can shunt excitatory input with an increase in membrane conductance, it also simultaneously decreases the membrane time constant leading to an increased firing rate, reducing the efficacy of shunting inhibition. This ineffectiveness in inhibitory signaling is especially prominent with either a depolarization in $\mathrm{E}_{\mathrm{GABA}}$ or when GABA is depolarizing at rest such as in MSNs (Prescott et al., 2006).

In addition to lateral inhibition between neighboring MSNs, GABA signaling in the striatum modulates dopaminergic innervation and in turn modulates reinforcement learning (Cox and Witten, 2019). Activation of the D1 and D2 dopamine receptors produce functionally opposing outcomes, with D1 receptor activation exciting direct pathway MSNs, while D2 activation inhibits indirect pathway MSNs (Surmeier et al., 2007; Tecuapetla et al., 2009). Notably, dopaminergic terminals projecting from the SNc and VTA also co-release GABA to inhibit striatal output (Tritsch et al., 2012). This finding was based on the timing of GABA conductance and IPSCs, which were observed to be significantly faster than would be expected if GABA were released by nearby interneurons; however, its possible that dopaminergic neurons activate GABA receptors indirectly. Striatal cholinergic interneurons (CINs) are another source of GABA, with roughly half of CINs demonstrating the ability to co-release acetylcholine and GABA (CGINs) (Lozovaya et al., 2018). In a model of PD, CGINs display impairments in excitation/inhibition balance due to dysregulated $\mathrm{Cl}^{-}$levels, which could be rescued by pharmacological NKCC1 inhibition. Interestingly, in the $\mathrm{zQ} 175^{ \pm}$mouse model of $\mathrm{HD}$, CINs demonstrated enhanced GABAergic inhibition, mediated by D2-MSN collaterals and not D1-MSNs (Lim and Surmeier, 2020). Multiple sources of striatal GABA could potentially increase $\mathrm{Cl}^{-}$accumulation and activity-dependent disinhibition in the striatum. Without a clear understanding of GABAergic neurophysiology in the healthy striatum, the challenge of understanding GABAergic dysregulation in the HD brain is even greater, as we explain below.

\section{Chloride Dynamics and Gamma-Amino Butyric Acid Signaling in the Huntington's Disease Striatum}

Alterations in GABA synapses have been demonstrated across a wide range of HD mouse models and corroborated in HD patients, which suggests reduced levels of striatal GABA (Perry et al., 1973; Spokes, 1980; Spokes et al., 1980). Because the impairments in GABA neurotransmission have already been extensively described [for review see references (Garret et al., 2018; Hsu et al., 2018)], we only highlight those impairments here. HD mouse models have demonstrated alterations in the subunit composition and distribution of $\mathrm{GABA}_{\mathrm{A}} \mathrm{Rs}$, resulting in impaired receptor kinetics and GABAergic tone (Hsu et al., 2018). Cortical and striatal neurons exhibit lower levels of
GAD65 and GAD67 (Urquhart et al., 1975), and GABA is consistently decreased across multiple rodent models and from post-mortem brain samples from HD patients (Perry et al., 1973; Spokes et al., 1980; Reynolds and Pearson, 1987). In line with this, electrophysiological recordings from R6/2 and Q175 demonstrate altered GABA-mediated $\mathrm{Cl}^{-}$currents in the striatum, cortex, and hippocampus (Cepeda et al., 2013; Wójtowicz et al., 2013; Hsu et al., 2018; Dargaei et al., 2019). $\mathrm{GABA}_{\mathrm{A}} \mathrm{R}$ subunit composition in the striatum is significantly altered leading to aberrant kinetics of $\mathrm{GABA}_{\mathrm{A}}$ currents, with differential expression of the $\alpha 1$ subunit, a key subunit for fast inhibitory synaptic currents (Vicini et al., 2001). The a2 subunit, a major component of $\mathrm{GABA}_{\mathrm{A}} \mathrm{Rs}$ in striatal MSNs is also decreased in R6/1 mice, consistent with the decreased GABAergic current in MSNs (Du et al., 2017). Taken together, altered $\mathrm{GABA}_{\mathrm{A}} \mathrm{R}$ subunit composition lead to complex changes in GABAergic neurotransmission, but whether these changes in striatal GABAergic inhibition result from direct or downstream effects of mHtt or whether they are a result of compensatory homeostatic mechanisms necessary to mitigate cortical hyperexcitability remains to be determined.

For instance, in presymptomatic mouse models of $\mathrm{HD}$, cortical glutamatergic input to MSNs is dysregulated, exhibiting increased amplitude (Cepeda et al., 2003) and increased frequency of spontaneous excitatory events (André et al., 2011; Raymond et al., 2011). At later stages of HD, increased glutamatergic input is replaced by a reduction in excitatory synaptic activity in MSNs and is accompanied by alterations in synaptic markers such as synaptophysin and PSD-95 (Cepeda et al., 2003). These findings reflect an early enhanced excitability of cortical pyramidal neurons (CPNs) and/or impairments in presynaptic inhibition of CPNs demonstrating early pathologically enhanced activity along the corticostriatal pathway. While the CPN-MSN connection progressive deteriorates, there is considerable loss of dendritic spines on MSNs, which occur at around the same time overt behavioral impairments begin to manifest (Cepeda et al., 2003). Strikingly, alterations in striatal GABAergic inhibition also demonstrates a biphasic pattern that is highly variable between mouse models (Hsu et al., 2018). In symptomatic HD mice, the frequency of $\mathrm{GABA}_{\mathrm{A}} \mathrm{R}$-mediated events is increased, and inhibitory input is increased onto MSNs (Cepeda et al., 2004). Although, these changes would indicate a reduced output of MSNs along both the direct and indirect pathways, changes in glutamate, GABA and dopamine differentially affect the direct and indirect pathway output (André et al., 2011; Barry et al., 2018; Plotkin and Goldberg, 2019), making it difficult to accurately predict the changes in BG circuitry. Given that $\mathrm{mHtt}$ is expressed in higher levels in the cortex compared to the striatum, one might predict that these regions would exhibit similar electrophysiological dysfunction or degeneration. However, since opposite changes in these two brain regions occur, it appears that neuronal dysfunction is not only mediated by a cell-autonomous mechanism (Creus-Muncunill and Ehrlich, 2019), but as previously discussed, the underlying network configuration may play a key role in the type of neuronal dysfunction. 


\section{D1- and D2-MSNs Differential Vulnerability in Huntington's Disease}

Although it is well accepted that D2-MSNs are affected earlier than D1-MSNs in HD, the mechanisms underlying this enhanced vulnerability remains unclear. Physiological and morphological differences between D1- and D2-MSNs are thought to underlie the preferential degeneration of D2MSNs. For example, D1-MSNs have an increased number of primary dendrites and greater extension of arborization, compared to D2-MSNs. These differences may contribute to different electrophysiological properties as D1-MSNs are known to have more hyperpolarized resting membrane potentials, a greater rheobase (Gertler et al., 2008), and lower intrinsic excitability (Willett et al., 2019). Moreover, D2-MSNs receive more cortical glutamatergic inputs, which also form larger synapses compared to those that synapse with D1-MSNs (Lei et al., 2004; Francelle et al., 2014). Taken together, these differences could render D2-MSNs more prone to excitotoxic damage, a hallmark feature in the mechanisms underlying neuronal dysfunction in HD (Cepeda et al., 2007; Cepeda and Levine, 2020). Despite the degeneration of D2-MSNs, some full-length mouse models of $\mathrm{HD}$ exhibit increased glutamatergic transmission in D1-MSNs earlier compared to D2-MSNs (André et al., 2011) and in the zQ175 knock-in model, D1-MSNs displayed more prominent morphological and electrophysiological changes (Goodliffe et al., 2018). This suggests that D1-MSNs experience increased sensitivity to the toxic effects of $\mathrm{mHtt}$ compared to D2-MSNs, although it is possible that D1-MSNs employ D1-specific intrinsic factors and/or mechanisms of compensation to provide some level of protection.

Selective vulnerability of D2-MSNs may also be a result of differential dopaminergic signaling. D2-MSNs display reduced phosphorylation of glycogen synthase kinase-3 (GSK3), which has been proposed to play a neuroprotective role HD (FernándezNogales et al., 2015). In contrast, pathologically increased GSK3 was reported to contribute to the pathogenesis of HD and inhibiting GSK3 has proven to be neuroprotective (Carmichael et al., 2002). The conflicting evidence regarding the involvement of GSK3 in HD likely stem from the opposing actions of the different GSK3 isoforms (D'Mello, 2021). GS3K $\beta$ phosphorylates Thr906-KCC2 and KCC2 activity (Watanabe et al., 2019), and inhibition of GSK3 $\beta$ enhances KCC2 expression and restores $\mathrm{E}_{\mathrm{GABA}}$ in a model of nerveinjury pain (Yeo et al., 2021). The potential effects of altered GSK3 activity on KCC2 activity in HD remains to be determined but offers an interesting and important avenue for exploration.

Transcriptomic analyses of single-nuclear RNA sequencing in striatal MSNs revealed differential responses of D1- and D2MSNs to mHtt toxicity (Lee et al., 2020). For example, D2MSNs exhibited an upregulation in the neurotrophin signaling pathway and a downregulation in mitochondrial oxidative phosphorylation (OXPHOS) mRNA followed by release of mitochondrial RNA, which occurred later in D1-MSNs. Although the BDNF receptor Ntrk2 was downregulated in both D1- and
D2-MSNs, only D2-MSNs exhibited an upregulation of Bdnf itself, which the authors suggested may be a D2-MSN-specific homeostatic response. Altogether, these functional differences between D1- and D2-MSNs calls for more targeted therapeutic strategies to combat cell-type specific excitotoxicity early on in D2-MSNs. The reasons for preferential neurodegeneration of D2-MSNs in HD and whether CCCs are dysregulated in both MSN subtypes remain elusive. Nonetheless, several potential mechanisms have yet to be addressed, which we discuss further.

\section{POTENTIAL MECHANISMS OF CATION-CHLORIDE COTRANSPORTER DYSFUNCTION IN HUNTINGTON'S DISEASE}

\section{Altered Protein-Protein Interaction Between $\mathrm{K}^{+}-\mathrm{Cl}^{-}$Co-transporter-2 and $\mathrm{mHtt}$}

Based on the unbiased Htt transcriptome studies and the findings from Dargaei et al. (2018), it remains unclear how the HD mutation leads to CCC dysfunction (Dargaei et al., 2018). Given that Htt and KCC2 interact (either directly or indirectly), it is unclear whether this interaction is altered in a gain-of-function or loss-of-function manner. The former would promote the interaction between $\mathrm{mHtt}$ and $\mathrm{KCC} 2$, and as $\mathrm{mHtt}$ forms cellular aggregates, enhanced binding would reduce $\mathrm{KCC} 2$ in the surface membrane, thereby reducing KCC2 activity. Along the same lines, mHtt sequestering KCC2 may also occur indirectly, via PACSIN1, a predominant interactor of KCC2, which could pull KCC2 from the membrane to restrict its surface expression (Figure 5; Mahadevan et al., 2017). Alternatively, it is possible that Htt could stabilize KCC2 in the membrane, a function that may be lost with $\mathrm{mHtt}$ much like the reduced interaction of $\mathrm{mHtt}$ and REST/NSRF in the regulation of BDNF transcription. If the former scenario is true, and $\mathrm{mHtt}$ aggregate formation leads to reduced KCC2 membrane expression, it remains to be determined whether this is true across all rodent models without the presence of nuclear aggregates or whether this occurs very early on before these aggregates are even formed (Menalled and Chesselet, 2002). Regardless, a depolarizing shift in $\mathrm{E}_{\mathrm{GABA}}$ may not necessitate aggregate formation, as the reversal of GABA polarity in $\mathrm{HD}$ is primarily due increased NKCC1 activity compared to decreased KCC2 function (Dargaei et al., 2018), despite there being no known interaction between NKCC1 and (m)Htt. Given that the changes in NKCC1 expression are present in presymptomatic HD mice, and in light of the novel neurodevelopmental emergence of the disease previously described, determining whether the "developmental" switch in GABA polarity even occurs is a possibility that warrants further examination. 


\section{Legend}

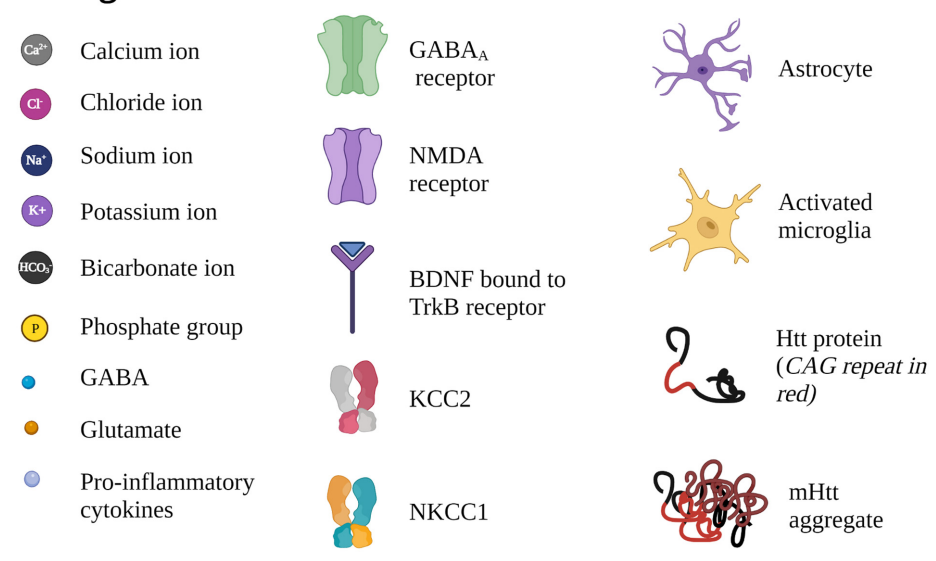

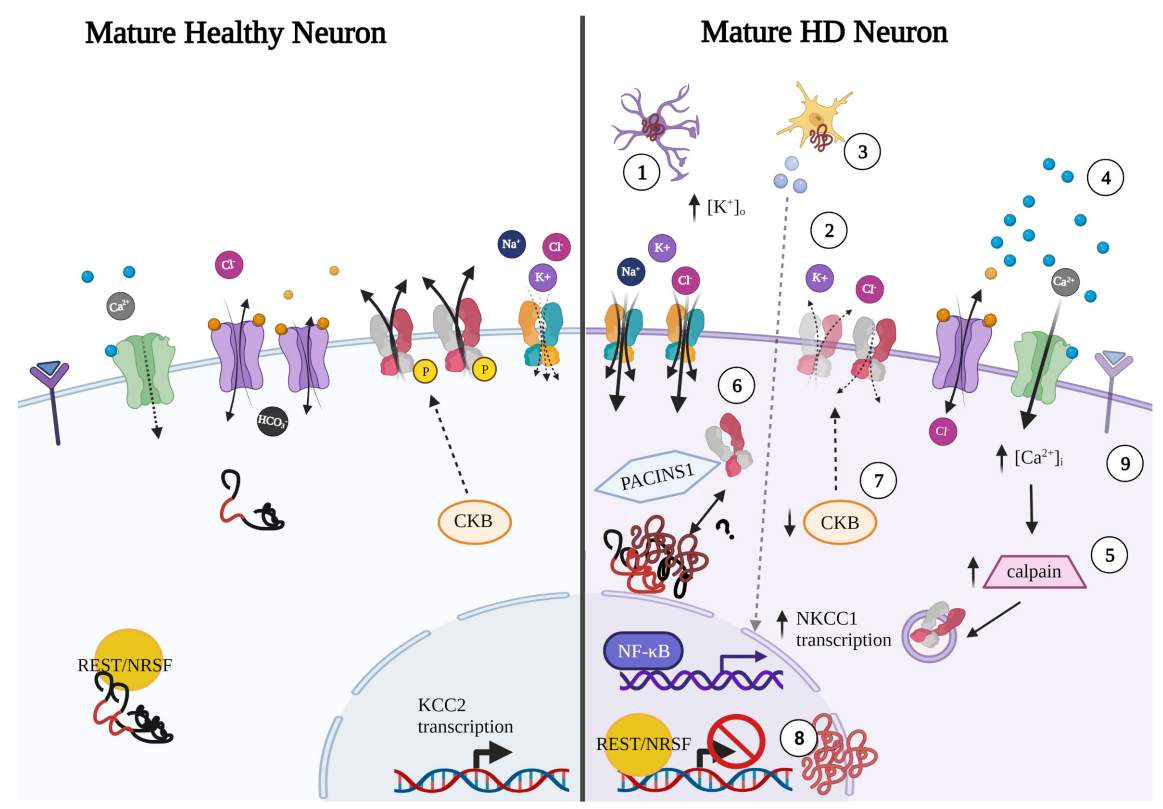

FIGURE 5 | Potential mechanisms underlying altered CCC expression and function in HD. (1) Impaired $K+$ homeostasis in astrocytes leads to local increases in extracellular $\left[\mathrm{K}^{+}\right.$. Since $\mathrm{Cl}^{-}$extrusion via $\mathrm{KCC} 2$ is driven by the $\mathrm{K}^{+}$concentration gradient, small changes in extracellular $\mathrm{K}^{+}$concentration (such as during sustained neuronal activity or neuronal excitability due increases in extracellular $\mathrm{K}^{+}$), can therefore (2) lead to reversal in the direction of ion transport to mitigate neuronal $\mathrm{K}^{+}$-mediated excitability. (3) Inflammatory-mediated upregulation of NKCC1 expression. NKCC1 transcripts are upregulated by the release of pro-inflammatory mediators released by activated microglia such as pro-inflammatory cytokine tumor necrosis factor alpha (TNF-alpha), which mediated by the nuclear factor kappa-light-chain-enhancer of activated B cells (NF-кB) pathway. (4) Glutamate-mediated excitotoxicity leads to calpain-mediated degradation of KCC2. Enhanced glutamate signaling leads to NMDA-mediated excitotoxic effects, resulting in increased $\mathrm{Ca}^{2+}$ influx. (5) Calcium-dependent protease, calpain, is well-studied in $\mathrm{HD}$ and is a strong negative regulator of KCC2 expression via cleavage of the C-terminal tail of KCC2 to reduce KCC2 expression. (6) Altered interaction between KCC2

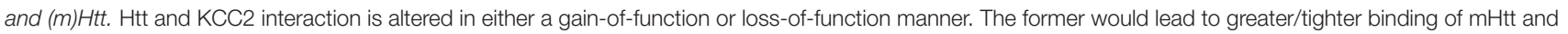
$\mathrm{KCC} 2$ and as $\mathrm{mHtt}$ forms cellular aggregates, enhanced binding would result in reduced $\mathrm{KCC} 2$ from the surface membrane to reduce $\mathrm{KCC} 2$ activity. $\mathrm{mHtt}$ sequestering KCC2 may occur indirectly, via protein kinase $\mathrm{C}$ and casein kinase II substrate in neurons (PACSIN1). PACSIN1 is known to be sequestered in mHtt aggregates and also forms strong interactions with $\mathrm{KCC} 2$, pulling $\mathrm{KCC} 2$ from the membrane to restrict surface expression. Alternatively, Htt may play some role in stabilizing KCC2 in the membrane, a function that may be lost with $\mathrm{mHTT}$ protein. (7) Reduced KCC2 function due to decrease in Brain-type creatine kinase (CKB) activity. CKB is an important player in regenerating of ATP through the phosphocreatine-creatine kinase system. The downregulation of CKB is well described as $\mathrm{mHtt}$ suppresses the activity of the promoter of the CKB gene, lowering somatic CKB expression in HD mice and human patients. CKB is a strong positive modulator of KCC2 activity, therefore $\mathrm{KCC} 2$ and $\mathrm{Cl}^{-}$dysregulation could be a result of the progressive downregulation of CKB in HD. CKB may enhance KCC2 in two ways: (i) CKB regenerates ATP required to regenerate the $\mathrm{K}^{+}$gradients that drive $\mathrm{KCC} 2 \mathrm{Cl}^{-}$extrusion (via $\mathrm{Na}^{+} / \mathrm{K}^{+}$ATPase) and (ii) CKB is known to phosphorylate KCC2 through its capacity to autophosphorylate. (8) Reduced transcription of KCC2 via pathological entry of REST/NRSF into the nucleus. Normal Htt binds to REST/NRSF from binding and reducing transcripts containing DNA repressor element (RE1) also referred to as neuron-restrictive silencer element (NRSE) sequences, which is recognized by the transcriptional silencer RE-1 silencing transcription factor (REST), also known as neuronal restrictive silencing factor, (NRSF). Normal Htt promotes transcription of RE-1-containing transcripts by sequestering REST/NRSF in the cytoplasm. In contrast, mHtt allows entry of REST/NRSF into the nucleus, which may reduce KCC2 transcripts. (9) Altered BDNF-TrkB signaling leads to altered KCC2 activity. The regulatory effects of BDNF on 
FIGURE 5 | KCC2 expression and function are dependent on activity and developmental stage. BDNF-TrkB signaling in immature neurons leads to the upregulation of KCC2 via ERK1/2 signaling, while in mature neurons BDNF-TrkB- mediated activation of the Ras/MAPK pathways leads to downregulation of KCC2. The underlying mechanism between BDNF-TrkB signaling on KCC2 expression in the context of HD remain unclear, however, it may be possible that there is a reversion to a neuronal immature state in order to "reboot" the system, leading to different regulatory effects of BDNF-TrkB on KCC2. Created with BioRender.com.

\section{Post-translational Modulators of $\mathrm{K}^{+}-\mathrm{Cl}^{-}$ Co-transporter-2 Expression Are Altered in Huntington's Disease: CKB and Calpain}

Creatine kinases (CKs) are important players in energy homeostasis, particularly for the regeneration of ATP through the phosphocreatine-creatine kinase system (Allen, 2012). The downregulation of Brain-type creatine kinase $(\mathrm{CKB})$ is well described in HD mouse models and human patients (Mochel et al., 2012; Lin et al., 2013), where $\mathrm{mHtt}$ is known to lower somatic CKB expression in primary neurons and striatum of HD mice (Lin et al., 2013). In the striatum of R6/2 mice, CKB protein expression is downregulated during the pre-symptomatic phase, however, the CKB transcript only decreases during late stages of the disease. A creatine-supplemented diet is sufficient to increase expression of $\mathrm{CKB}$, reduce aggregate formation (Lin et al., 2013), and improve motor dysfunction and hearing impairments in R6/2 mice (Ferrante et al., 2000). Given that CKB is a strong positive modulator of KCC2 activity, where suppression of CKB activity leads to reduced KCC2 function (Inoue et al., 2006), it is possible that the depolarization of $\mathrm{E}_{\mathrm{GABA}}$ and $\mathrm{Cl}^{-}$dysregulation could be a result of the progressive downregulation of $\mathrm{CKB}$ in $\mathrm{HD}$ (Figure 5). The positive modulation of CKB on KCC2 happens in two ways: (i) CKB regenerates ATP necessary to regenerate the $\mathrm{K}^{+}$gradients that drive $\mathrm{KCC} \mathrm{Cl}^{-}$extrusion (via $\mathrm{Na}^{+} / \mathrm{K}^{+}$ATPase) and (ii) CKB phosphorylates KCC2 to increase activity (Hemmer et al., 1995; Inoue et al., 2004). Therefore, the beneficial effects of $\mathrm{CKB}$ in $\mathrm{HD}$ may also indirectly enhance $\mathrm{KCC} 2$, a possibility worth exploring.

KCC2 activity is also regulated by calpain, a calciumdependent protease that has been implicated in many neurological diseases such as traumatic brain injury, neuropathic pain, and epilepsy (Ono et al., 2016; Lam et al., 2017). Calpain activation is well-studied in HD, as it plays a role in cleavage of $\mathrm{Htt}$ in the caudate of $\mathrm{HD}$ patients (Gafni and Ellerby, 2002), and inhibition of calpain is known to reduce toxicity (Gafni et al., 2004). The negative effects of calpain on KCC2 are well-documented and are a common cause of disinhibition in neurodegenerative disorders, as NMDAR-mediated excitotoxicity results in calpain-mediated cleavage of the C-term tail of KCC2 (Figure 5; Lee et al., 2011; Puskarjov et al., 2012). During seizure onset, m-calpain is excessively activated and KCC2 expression can be restored with a calpain inhibitor (Wan et al., 2018). Interestingly, seizures are observed in $\sim 40 \%$ of early onset $\mathrm{HD}$ patients but are relatively rare in adult-onset HD patients (Cloud et al., 2012). This phenomenon is also observed in mouse models, where R6/2 mice display increased susceptibility to seizures, although it is rare in full-length models with more protracted development of symptoms (Ferrante, 2009). Whether the beneficial effects of calpain inhibition also indirectly act on KCC2 surface stability (along with Htt levels) in HD remain to be determined.

\section{Reduction of BDNF in Huntington's Disease and Its Impact on $\mathrm{K}^{+}-\mathrm{Cl}^{-}$ Co-transporter-2 Expression}

As previously outlined, $\mathrm{Htt}$ functions to positively regulate BDNF transcription by preventing REST/NRSF from binding and reducing $b d n f$ transcripts (Zuccato et al., 2003). Based on this regulatory function of $\mathrm{Htt}$, it has been postulated that $\mathrm{Htt}$ acts as a general regulator of transcription RE1/NRSEs-containing genes through the interaction with REST/NRSF. One such transcript is SLC12A5, which contains two RE-1 sites; one located in the $5^{\prime}$ promoter region of KCC2b, which acts in concert with intronic RE-1 to repress the KCC2b transcripts (Yeo et al., 2009). Therefore, it is reasonable to suggest that due to the loss-offunction of mHTT, pathological entry of REST/NRSF into the nucleus may also reduce KCC2 transcription.

The regulatory effects of $\mathrm{BDNF}$ on $\mathrm{KCC} 2$ expression and function are complex and depend on both activity and developmental stage. In immature neurons, BDNF-TrkB signaling leads to the upregulation of $\mathrm{KCC} 2$ in an activitydependent manner via ERK1/2 signaling (Uvarov et al., 2006), while in mature neurons, BDNF activation of TrkB receptors downregulates KCC2 surface expression in an activitydependent manner (Rivera et al., 2002, 2004). This BDNF-TrkB mediated downregulation of KCC2 is well-characterized and underlies impaired KCC2 activity in many neuropathologies (Liu et al., 2019a; Pradhan et al., 2019), which lends strength to the hypothesis that alterations in BDNF signaling underlie KCC2 dysfunction in HD. This hypothesis is supported by experimentation where bath application of BDNF reduced the frequency of spontaneous GABAergic synaptic currents in R6/2 MSNs, further strengthening the link between BDNF and synaptic inhibition (Cepeda et al., 2004). Notably, TrkB expression is higher in D2-MSNs compared to D1-MSNs, which may lead to more pronounced effects of aberrant BDNF-TrkB signaling in D2-MSNs (Baydyuk and $\mathrm{Xu}, 2014$ ). However, as outlined above, only D2-MSNs exhibited an upregulation of $B d n f$, even though TrkB transcripts were downregulated in both D1 and D2-MSNs (Lee et al., 2020), which could potentially lead to even greater KCC2 dysfunction in the already vulnerable MSN subtype. Taken together, the increased baseline TrkB expression, enhanced HD-associated $B d n f$ increase and its implications on KCC2 function, could provide some insight into how KCC2 and $\mathrm{Cl}^{-}$regulation may collapse more readily in D2-MSNs. Although, these finding present a logical yet puzzling assumption: with a loss of BDNF in HD, KCC2 levels should be left unchecked, 
therefore enhancing KCC2 function. Considering the complex pathways and context-dependent effects BDNF-TrkB signaling has on KCC2 expression, it is difficult to tease apart in HD. However, in many neurological disorders, a reversion to a neuronal immature state to "reboot" the system, might lead to different regulatory effects of $\mathrm{BDNF}-\mathrm{TrkB}$ on $\mathrm{KCC} 2$, that have yet to be explored.

\section{Inflammatory-Mediated Upregulation of $\mathrm{Na}^{+}-\mathrm{K}^{+}-\mathrm{Cl}^{-}$Co-transporter-1 Expression}

The transcriptional upregulation of NKCC1 by cytokines and inflammation has been previously described, such as during pulmonary edema (Weidenfeld and Kuebler, 2017). As previously outlined, cytokine-mediated upregulation of NKCC1 transcription and protein expression have been demonstrated in the striatum of HD mice, leading to motor deficits (Figure 5; Hsu et al., 2019). Here, the authors validated cytokine-mediated upregulation of NKCC1 expression by incubating STHdH97 cells with the pro-inflammatory cytokine tumor necrosis factor alpha (TNF-alpha), mediated by the nuclear factor kappalight-chain-enhancer of activated $\mathrm{B}$ cells $(\mathrm{NF}-\kappa \mathrm{B})$ pathway. In $\mathrm{HD}$, inflammation is most prominent during the final stages, suggesting that upregulation of NKCC1 may occur at later stages, though CCC changes were already evident in presymptomatic R6/2 mice (Dargaei et al., 2018). Activation of the D2 receptors (and not D1 receptors) can activate PP2A and inhibit the production of inflammatory cytokines and chemokines (Han et al., 2017); because PP2A can dephosphorylate Ser940 on KCC2 (Lee, 2009), it is possible that enhanced dopamine signaling early in HD (Chen et al., 2013) leads to an early PP2Amediated reduction of KCC2 activity specifically on D2-MSNs. The activation of $\mathrm{PP} 2 \mathrm{~A}$ via D2 receptor activation would then produce two important effects on $\mathrm{Cl}^{-}$regulation: (i) KCC2 downregulation via Ser940 dephosphorylation via PP2A (Lee et al., 2011) and/or (ii) the reduction of inflammatory cytokines production (Han et al., 2017), which could reduce NKCC1 transcripts. Therefore, it may be possible that reduced KCC2 function may be due to D2 receptor-mediated upregulation of $\mathrm{PP} 2 \mathrm{~A}$ or that it is a by-product in an attempt reduce inflammatory cytokine production.

\section{Reversal of Chloride Transport Through Increased $\mathrm{K}^{+}$Extracellular Concentration}

So far, the focus on KCC2 dysfunction has been on $\mathrm{Cl}^{-}$dynamics and its deleterious effects on synaptic inhibition, but as KCC2 cotransports $\mathrm{K}^{+}$and $\mathrm{Cl}^{-}, \mathrm{K}^{+}$regulation inextricably becomes dysregulated. KCC2 extrudes $\mathrm{Cl}^{-}$through a secondary active transport mechanism and is driven by the $\mathrm{K}^{+}$concentration gradient. Thus, the direction of $\mathrm{Cl}^{-}$transport can be reversed by even small changes in extracellular $\mathrm{K}^{+}$concentration, which can occur during sustained neuronal activity to buffer extracellular $\mathrm{K}^{+}$(Thompson and Gähwiler, 1989; Payne, 1997; Chamma et al., 2012). Therefore, under high stimulation and without KCC2 to re-establish $\mathrm{Cl}^{-}$gradients, the local build up of $\mathrm{K}^{+}$ extracellular would further accelerate the progressive weakening of GABAergic currents. In HD, striatal MSNs have elevated levels of extracellular $\mathrm{K}^{+}$, due to abnormal astrocyte-mediated $\mathrm{K}^{+}$ homeostasis via impaired Kir4.1 channels, leading to neuronal excitability (Figure 5; Tong et al., 2014), which could lead to a reversal in the direction of ion transport via KCC2 to mitigate neuronal $\mathrm{K}^{+}$-mediated excitability.

\section{CATION-CHLORIDE COTRANSPORTERS AS THERAPEUTIC TARGETS}

\section{Overview}

Although the alterations in GABA neurotransmission are well characterized in $\mathrm{HD}$, drugs that target GABA signaling have proven to be limited. For instance, clinical trials using synthetic agonists of $\delta$ - containing $\mathrm{GABA}_{\mathrm{A}}$ Rs (Foster et al., 1983) and the GABA analog, muscimol (Shoulson et al., 1977) failed to improve motor or cognitive function in HD patients. However, when we consider CCCs as the root cause of impaired inhibition in $\mathrm{HD}$, these results may not be surprising. Increasing the GABAergic conductance would still impose a $\mathrm{Cl}^{-}$load on neurons which could exacerbate synaptic dysfunction (Prescott et al., 2006). Therefore, the goal should be directed to restoring $\mathrm{Cl}^{-}$homeostasis and thereby inhibition rather than increasing GABAergic transmission, which would be counterproductive without mechanisms to re-establish the $\mathrm{Cl}^{-}$gradient, as we outline below.

\section{Targeting $\mathrm{Na}^{+}-\mathrm{K}^{+}-\mathrm{Cl}^{-}$Co-transporter-1}

The FDA-approved diuretic, bumetanide, has proven to be beneficial in rescuing various symptoms of many neurological disorders for decades (Puskarjov et al., 2014; Ben-Ari, 2017). Bumetanide blocks NKCC1 activity at low doses to restore physiological intracellular $\mathrm{Cl}^{-}$levels and GABAergic inhibition, and has been successful in treating core symptoms in epilepsy, various models of autism, schizophrenia, pain, PD, Down syndrome, and brain trauma (Ben-Ari, 2017). As bumetanide has been used for decades, the side-effects have been well characterized (Ben-Ari, 2017), and are due to off-target effects on the peripherally expressed NKCC2, which is found in the kidney (Igarashi et al., 1996). Moreover, due to bumetanide's systemic administration, low brain-plasma ratio of bumetanide due to low blood-brain barrier permeability have cast doubt on bumetanide's ability to act on the brain (Römermann et al., 2017). To address these concerns, a novel, selective and safe NKCC1 inhibitor called ARN23746 was recently discovered (Savardi et al., 2020). ARN23746 is metabolically stable, exhibits high solubility and could restore core symptoms in mouse models of Down syndrome and autism. More importantly, ARN23746 displayed no off-target effects and no toxicity with chronic treatment in vivo. Thus, the development of selective chemical inhibitors such as ARN2376 continue to allow key players in $\mathrm{Cl}^{-}$regulation to remain promising druggable targets. 


\section{Targeting $\mathrm{K}^{+}-\mathrm{Cl}^{-}$Co-transporter-2}

$\mathrm{K}^{+}-\mathrm{Cl}^{-}$co-transporter-2 is a prime target for restoring $\mathrm{Cl}^{-}$ homeostasis due to the reduced likelihood of developing adverse side effects as it is neuron-specific, operates under isotonic conditions and does not contribute to volume regulation (Kahle et al., 2008). In addition, KCC2 operates near its equilibrium point (Buzsáki et al., 2007) and increasing $\mathrm{Cl}^{-}$extrusion capacity beyond physiological levels is unlikely as the ability of inhibition to reach pathological levels are restricted by the non-linear relationship between $\mathrm{KCC} 2$ and $\mathrm{E}_{\mathrm{GABA}}$ (Doyon et al., 2011, 2016) and is constrained by $\mathrm{E}_{\mathrm{K}}{ }^{+}$(Düsterwald et al., 2018). However, one might consider the possibility that enhanced KCC2 may lead to pathological accumulation of extracellular $\mathrm{K}^{+}$, which could increase neuronal excitability (Kaila et al., 1997). However, large shifts in the driving force of $\mathrm{Cl}^{-}$due to enhanced KCC2 activity exhibited only subtle changes in volume $(<1 \%)$ and KCC2 expression proved to have very little correlation with the neuronal membrane potential (Düsterwald et al., 2018). Since excess neuronal firing is the primary culprit of increased extracellular $\mathrm{K}^{+}$ (and hence pathological neuronal excitability) (Doyon et al., 2011, 2016), enhancing KCC2 function to decrease excess firing provides further support for $\mathrm{KCC} 2$ as a promising therapeutic target.

To enhance KCC2 function, the CLP series (CLP265, -290, -657) of $\mathrm{Cl}^{-}$extrusion enhancers have been developed; they are reported to enhance KCC2 membrane expression, lower intracellular $\mathrm{Cl}^{-}$levels and restore core symptoms in rodent models of neuropathic pain (Gagnon et al., 2013). CLP drugs have since then been extended to treat a wide range of diseases but despite their effectiveness, they have a few caveats. The timing of administration is critical, and the mechanism of action is not fully known, which has been suggested to act on $\mathrm{GABA}_{\mathrm{A}} \mathrm{Rs}$ (versus KCC2) (Cardarelli et al., 2017). Despite this, CLP’s proven effectiveness and increasing use in a variety of diseased models offers hope for the use of KCC2 as a continued therapeutic target.

Recently, post-translational regulators have been an alternative approach to enhance KCC2 activity (Zhang et al., 2020). For instance, using an inhibitor of the master CCC regulator SPAK kinase (STK39), called ZT-1a, researchers were able to mitigate cerebral infarction in a model of ischemic stroke. Targeting SPAK kinases is a powerful way of regulating $\mathrm{Cl}^{-}$as it can simultaneously inhibit NKCC1 and activate KCC2 (Huang et al., 2019), thus proving to be an effective approach to modulate CCCs for various neurological disorders.

\section{REFERENCES}

Abdi, A., Mallet, N., Mohamed, F. Y., Sharott, A., Dodson, P. D., Nakamura, K. C., et al. (2015). Prototypic and Arkypallidal Neurons in the Dopamine-Intact External Globus Pallidus. J. Neurosci. 35, 6667-6688. doi: 10.1523/jneurosci. 4662-14.2015

Akopian, G., Barry, J., Cepeda, C., and Levine, M. S. (2016). Altered Membrane Properties and Firing Patterns of External Globus Pallidus Neurons in the R6/2 Mouse Model of Huntington's Disease. J. Neurosci. Res. 94, 1400-1410. doi: 10.1002/jnr.23889

Albin, R. L. (1995). Selective Neurodegeneration in Huntington's Disease. Ann. Neurol. 38, 835-836.

\section{CONCLUSION}

$\mathrm{K}^{+}-\mathrm{Cl}^{-}$Co-transporter-2 and NKCC1 regulate steady-state intracellular $\mathrm{Cl}^{-}$gradients and consequently, the direction and strength of GABAergic transmission. During neuropathological insult, neurons revert to a phenotypically immature state with increased $\mathrm{Cl}^{-}$levels, leading to depolarizing effects of GABA. Several lines of evidence presented here, demonstrate an important link between CCC dysfunction and HD (Dargaei et al., 2018; Hsu et al., 2019), though the mechanisms underlying this dysfunction remain unclear. HD is a multi-factorial disease, with no effective treatments or cure and sadly, many of the current therapeutic strategies are limited by the late detection of the disease. As outlined here, CCC-targeted therapies have proven to ameliorate the cognitive and motor impairments associated with HD in both presymptomatic and symptomatic mouse models, providing a novel therapeutic strategy.

In this review, we summarized key pieces of experimental evidence that underscores the importance of $\mathrm{Cl}^{-}$regulation and GABA signaling in the healthy and diseased BG neural circuit and how the underlying network topology may render the BG susceptible to activity-dependent disinhibition. Based on this knowledge, it becomes clear why drugs used to enhance GABA conductance have failed to improve HD symptoms in clinical trials. We also present possible mechanisms that may underlie CCC dysfunction, although given the complexity of the disease, further investigation is necessary to uncover the exact mechanisms. Given the developmental defects present in HD and the importance of CCC during neurodevelopment, future experimental work during various developmental stages is needed to explore this possibility to uncover novel therapeutic avenues.

\section{AUTHOR CONTRIBUTIONS}

MS drafted the review and created the figures. MW revised and finalized the review. Both authors contributed to the article and approved the submitted version.

\section{FUNDING}

This work was supported by a grant to MW from the Canadian Institutes of Health Research (CIHR).

Albin, R. L., Reiner, A., Anderson, K. D., Dure, L. S. IV, Handelin, B., Balfour, R., et al. (1992). Preferential Loss of Striato-External Pallidal Projection Neurons in Presymptomatic Huntington's Disease. Ann. Neurol. 31, 425-430. doi: 10.1002/ana.410310412

Albin, R. L., Young, A. B., and Penney, J. B. (1989). The Functional Anatomy of Basal Ganglia Disorders. Trends Neurosci. 12, 366-375. doi: 10.1016/01662236(89)90074- $\mathrm{x}$

Alexander, G. E., and Crutcher, M. D. (1990). Functional Architecture of Basal Ganglia Circuits: Neural Substrates of Parallel Processing. Trends Neurosci. 13, 266-271. doi: 10.1016/0166-2236(90)90107-1

Alexander, G. E., DeLong, M. R., and Strick, P. L. (1986). Parallel Organization of Functionally Segregated Circuits Linking Basal Ganglia 
and Cortex. Annu. Rev. Neurosci. 9, 357-381. doi: 10.1146/annurev.ne.09. 030186.002041

Allen, P. J. (2012). Creatine Metabolism and Psychiatric Disorders: Does Creatine Supplementation Have Therapeutic Value? Neurosci. Biobehav. Rev. 36, 14421462. doi: 10.1016/j.neubiorev.2012.03.005

André, V. M., Cepeda, C., Fisher, Y. E., Huynh, M., Bardakjian, N., Singh, S., et al. (2011). Differential Electrophysiological Changes in Striatal Output Neurons in Huntington's Disease. J. Neurosci. 31, 1170-1182. doi: 10.1523/jneurosci.353910.2011

Andrew, S. E., Goldberg, Y. P., Kremer, B., Telenius, H., Theilmann, J., Adam, S., et al. (1993). The Relationship between Trinucleotide (Cag) Repeat Length and Clinical Features of Huntington's Disease. Nat. Gen. 4, 398-403. doi: 10.1038/ ng0893-398

Arroyo, J. P., Kahle, K. T., and Gamba, G. (2013). The Slc12 Family of Electroneutral Cation-Coupled Chloride Cotransporters. Mol. Aspects Med. 34, 288-298. doi: 10.1016/j.mam.2012.05.002

Barnat, M., Capizzi, M., Aparicio, E., Boluda, S., Wennagel, D., Kacher, R., et al. (2020). Huntington's Disease Alters Human Neurodevelopment. Science 369, 787-793. doi: 10.1126/science.aax3338

Barnat, M., Le Friec, J., Benstaali, C., and Humbert, S. (2017). Huntingtin-Mediated Multipolar-Bipolar Transition of Newborn Cortical Neurons Is Critical for Their Postnatal Neuronal Morphology. Neuron 93, 99-114. doi: 10.1016/j. neuron.2016.11.035

Barry, J., Akopian, G., Cepeda, C., and Levine, M. S. (2018). Striatal Direct and Indirect Pathway Output Structures Are Differentially Altered in Mouse Models of Huntington's Disease. J. Neurosci. 38, 4678-4694. doi: 10.1523/jneurosci. 0434- 18.2018

Baydyuk, M., and Xu, B. (2014). Bdnf Signaling and Survival of Striatal Neurons. Front. Cell Neurosci. 8:254. doi: 10.3389/fncel.2014.00254

Ben-Ari, Y. (2002). Excitatory Actions of Gaba During Development: The Nature of the Nurture. Nat. Rev. Neurosci. 3, 728-739. doi: 10.1038/nrn920

Ben-Ari, Y. (2017). Nkccl Chloride Importer Antagonists Attenuate Many Neurological and Psychiatric Disorders. Trends Neurosci. 40, 536-554. doi: 10.1016/j.tins.2017.07.001

Ben-Ari, Y., Cherubini, E., Corradetti, R., and Gaiarsa, J. L. (1989). Giant Synaptic Potentials in Immature Rat Ca3 Hippocampal Neurones. J. Physiol. 416, $303-$ 325. doi: 10.1113/jphysiol.1989.sp017762

Ben-Ari, Y., Gaiarsa, J.-L., Tyzio, R., and Khazipov, R. (2007). Gaba: A Pioneer Transmitter That Excites Immature Neurons and Generates Primitive Oscillations. Physiol. Rev. 87, 1215-1284. doi: 10.1152/physrev.00017.2006

Ben-Ari, Y., Khalilov, I., Kahle, K. T., and Cherubini, E. (2012a). The Gaba Excitatory/Inhibitory Shift in Brain Maturation and Neurological Disorders. Neuroscientist 18, 467-486. doi: 10.1177/1073858412438697

Ben-Ari, Y., Woodin, M. A., Sernagor, E., Cancedda, L., Vinay, L., Rivera, C., et al. (2012b). Refuting the Challenges of the Developmental Shift of Polarity of Gaba Actions: Gaba More Exciting Than Ever! Front. Cell Neurosci. 6:35. doi: 10.3389/fncel.2012.00035

Blaesse, P., Airaksinen, M. S., Rivera, C., and Kaila, K. (2009). Cation-Chloride Cotransporters and Neuronal Function. Neuron 61, 820-838. doi: 10.1016/j. neuron.2009.03.003

Blaesse, P., and Schmidt, T. (2015). K-Cl Cotransporter Kcc2-a Moonlighting Protein in Excitatory and Inhibitory Synapse Development and Function. Pflug. Arch. Eur. J. Physiol. 467, 615-624. doi: 10.1007/s00424-014-1547-6

Bregestovski, P., and Bernard, C. (2012). Excitatory Gaba: How a Correct Observation May Turn out to Be an Experimental Artifact [Hypothesis and Theory]. Front. Pharmacol. 3:65. doi: 10.3389/fphar.2012.00065

Burke, D. A., Rotstein, H. G., and Alvarez, V. A. (2017). Striatal Local Circuitry: A New Framework for Lateral Inhibition. Neuron 96, 267-284. doi: 10.1016/j. neuron.2017.09.019

Buzsáki, G., Kaila, K., and Raichle, M. (2007). Inhibition and Brain Work. Neuron 56, 771-783. doi: 10.1016/j.neuron.2007.11.008

Capizzi, M., Carpentier, R., Denarier, E., Adrait, A., Kassem, R., Mapelli, M., et al. (2021). Developmental Defects in Huntington's Disease Show That Axonal Growth and Microtubule Reorganization Require Numa1. Neuron [Preprint]. doi: 10.1016/j.neuron.2021.10.033

Cardarelli, R. A., Jones, K., Pisella, L. I., Wobst, H. J., McWilliams, L. J., Sharpe, P. M., et al. (2017). The Small Molecule Clp257 Does Not Modify Activity of the $\mathrm{K}(+)-\mathrm{Cl}(-)$ Co-Transporter Kcc2 but Does Potentiate Gaba(a) Receptor Activity. Nat. Med. 23, 1394-1396. doi: 10.1038/nm.4442

Carmichael, J., Sugars, K. L., Bao, Y. P., and Rubinsztein, D. C. (2002). Glycogen Synthase Kinase-3beta Inhibitors Prevent Cellular Polyglutamine Toxicity Caused by the Huntington's Disease Mutation. J. Biol. Chem. 277, 33791-33798. doi: 10.1074/jbc.M204861200

Carter, R. J., Lione, L. A., Humby, T., Mangiarini, L., Mahal, A., Bates, G. P., et al. (1999). Characterization of Progressive Motor Deficits in Mice Transgenic for the Human Huntington's Disease Mutation. J. Neurosci. 19, 3248-3257. doi: 10.1523/jneurosci.19-08-03248.1999

Cepeda, C., and Levine, M. S. (2020). Synaptic Dysfunction in Huntington's Disease: Lessons from Genetic Animal Models. Neuroscientist 2020:1073858420972662. doi: 10.1177/1073858420972662

Cepeda, C., Galvan, L., Holley, S. M., Rao, S. P., André, V. M., Botelho, E. P., et al. (2013). Multiple Sources of Striatal Inhibition Are Differentially Affected in Huntington's Disease Mouse Models. J. Neurosci. 33, 7393-7406. doi: 10.1523/ jneurosci.2137-12.2013

Cepeda, C., Hurst, R. S., Calvert, C. R., Hernández-Echeagaray, E., Nguyen, O. K., Jocoy, E., et al. (2003). Transient and Progressive Electrophysiological Alterations in the Corticostriatal Pathway in a Mouse Model of Huntington's Disease. J. Neurosci. 23, 961-969. doi: 10.1523/jneurosci.23-03-00961.2003

Cepeda, C., Starling, A. J., Wu, N., Nguyen, O. K., Uzgil, B., Soda, T., et al. (2004). Increased Gabaergic Function in Mouse Models of Huntington's Disease: Reversal by Bdnf. J. Neurosci. Res. 78, 855-867. doi: 10.1002/jnr.20344

Cepeda, C., Wu, N., André, V. M., Cummings, D. M., and Levine, M. S. (2007). The Corticostriatal Pathway in Huntington's Disease. Prog. Neurobiol. 81, 253-271. doi: 10.1016/j.pneurobio.2006.11.001

Chahrour, M., Jung, S. Y., Shaw, C., Zhou, X., Wong, S. T., Qin, J., et al. (2008). Mecp2, a Key Contributor to Neurological Disease, Activates and Represses Transcription. Science 320, 1224-1229. doi: 10.1126/science.1153252

Chamma, I., Chevy, Q., Poncer, J. C., and Levi, S. (2012). Role of the Neuronal $\mathrm{K}-\mathrm{Cl} \mathrm{Co}-\mathrm{Transporter} \mathrm{Kcc} 2$ in Inhibitory and Excitatory Neurotransmission [Review]. Front. Cell. Neurosci. 6:5. doi: 10.3389/fncel.2012.00005

Chen, B., Li, Y., Yu, B., Zhang, Z., Brommer, B., Williams, P. R., et al. (2018). Reactivation of Dormant Relay Pathways in Injured Spinal Cord by Kcc2 Manipulations. Cell 174, 521.e-535.e. doi: 10.1016/j.cell.2018.06.005

Chen, J. Y., Wang, E. A., Cepeda, C., and Levine, M. S. (2013). Dopamine Imbalance in Huntington's Disease: A Mechanism for the Lack of Behavioral Flexibility. Front. Neurosci. 7:114. doi: 10.3389/fnins.2013.00114

Chew, T. A., Orlando, B. J., Zhang, J., Latorraca, N. R., Wang, A., Hollingsworth, S. A., et al. (2019). Structure and Mechanism of the Cation-Chloride Cotransporter Nkccl. Nature 572, 488-492. doi: 10.1038/s41586-019-1438-2

Chi, X., Li, X., Chen, Y., Zhang, Y., Su, Q., and Zhou, Q. (2021). CryoEm Structures of the Full-Length Human Kcc2 and Kcc3 Cation-Chloride Cotransporters. Cell Res. 31, 482-484.

Chobanian, A. V., Bakris, G. L., Black, H. R., Cushman, W. C., Green, L. A., Izzo, J. L. Jr., et al. (2003). The Seventh Report of the Joint National Committee on Prevention, Detection, Evaluation, and Treatment of High Blood Pressure: The Jnc 7 Report. JAMA 289, 2560-2572. doi: 10.1001/jama.289.19.2560

Cloud, L. J., Rosenblatt, A., Margolis, R. L., Ross, C. A., Pillai, J. A., CoreyBloom, J., et al. (2012). Seizures in Juvenile Huntington's Disease: Frequency and Characterization in a Multicenter Cohort. Mov. Disord. 27, 1797-1800. doi: $10.1002 / \mathrm{mds} .25237$

Cox, J., and Witten, I. B. (2019). Striatal Circuits for Reward Learning and Decision-Making. Nat. Rev. Neurosci. 20, 482-494. doi: 10.1038/s41583-0190189-2

Creus-Muncunill, J., and Ehrlich, M. E. (2019). Cell-Autonomous and Non-CellAutonomous Pathogenic Mechanisms in Huntington's Disease: Insights from in Vitro and in Vivo Models. Neurothera 16, 957-978. doi: 10.1007/s13311-01900782-9

Crossman, A. R. (1987). Primate Models of Dyskinesia: The Experimental Approach to the Study of Basal Ganglia-Related Involuntary Movement Disorders. Neurosci 21, 1-40. doi: 10.1016/0306-4522(87)90322-8

Da Cunha, C., Boschen, S. L., Gómez, A. A., Ross, E. K., Gibson, W. S., Min, H. K., et al. (2015). Toward Sophisticated Basal Ganglia Neuromodulation: Review on 
Basal Ganglia Deep Brain Stimulation. Neurosci. Biobehav. Rev. 58, 186-210. doi: 10.1016/j.neubiorev.2015.02.003

Dargaei, Z., Bang, J. Y., Mahadevan, V., Khademullah, C. S., Bedard, S., Parfitt, G. M., et al. (2018). Restoring Gabaergic Inhibition Rescues Memory Deficits in a Huntington's Disease Mouse Model. Proc. Natl. Acad. Sci. U S A. 115, E1618-E1626. doi: 10.1073/pnas.1716871115

Dargaei, Z., Liang, X., Serranilla, M., Santos, J., and Woodin, M. A. (2019). Alterations in Hippocampal Inhibitory Synaptic Transmission in the R6/2 Mouse Model of Huntington's Disease. Neurosci 404, 130-140. doi: 10.1016/j. neuroscience.2019.02.007

de Los Heros, P., Alessi, D. R., Gourlay, R., Campbell, D. G., Deak, M., Macartney, T. J., et al. (2014). The Wnk-Regulated Spak/Osr1 Kinases Directly Phosphorylate and Inhibit the K+-Cl- Co-Transporters. Biochem. J. 458, 559573. doi: $10.1042 / \mathrm{bj} 20131478$

Delpire, E., and Gagnon, K. B. (2018). $\mathrm{Na}(+)-\mathrm{K}(+)-2 \mathrm{cl}(-)$ Cotransporter (Nkcc) Physiological Function in Nonpolarized Cells and Transporting Epithelia. Compr. Physiol. 8, 871-901. doi: 10.1002/cphy.c170018

Dickey, A. S., and La Spada, A. R. (2018). Therapy Development in Huntington Disease: From Current Strategies to Emerging Opportunities. Am. J. Med. Genet. 176, 842-861. doi: 10.1002/ajmg.a.38494

D'Mello, S. R. (2021). When Good Kinases Go Rogue: Gsk3, P38 Mapk and Cdks as Therapeutic Targets for Alzheimer's and Huntington's Disease. Int. J. Mol. Sci. 22:11. doi: 10.3390/ijms22115911

Domaradzki, J. (2015). The Impact of Huntington Disease on Family Carers: A Literature Overview. Psychiatr. Pol. 49, 931-944. doi: 10.12740/pp/34496

Doyon, N., Prescott, S. A., Castonguay, A., Godin, A. G., Kröger, H., and De Koninck, Y. (2011). Efficacy of Synaptic Inhibition Depends on Multiple, Dynamically Interacting Mechanisms Implicated in Chloride Homeostasis. PLoS Comput. Biol. 7:e1002149. doi: 10.1371/journal.pcbi.1002149

Doyon, N., Vinay, L., Prescott, S. A., and De Koninck, Y. (2016). Chloride Regulation: A Dynamic Equilibrium Crucial for Synaptic Inhibition. Neuron 89, 1157-1172. doi: 10.1016/j.neuron.2016.02.030

Du, Z., Tertrais, M., Courtand, G., Leste-Lasserre, T., Cardoit, L., Masmejean, F., et al. (2017). Differential Alteration in Expression of Striatal Gaba(a)R Subunits in Mouse Models of Huntington's Disease. Front. Mol. Neurosci. 10:198. doi: 10.3389/fnmol.2017.00198

Düsterwald, K. M., Currin, C. B., Burman, R. J., Akerman, C. J., Kay, A. R., and Raimondo, J. V. (2018). Biophysical Models Reveal the Relative Importance of Transporter Proteins and Impermeant Anions in Chloride Homeostasis. Elife 7:39575. doi: 10.7554/eLife. 39575

Dzhala, V. I., Brumback, A. C., and Staley, K. J. (2008). Bumetanide Enhances Phenobarbital Efficacy in a Neonatal Seizure Model. Ann. Neurol. 63, 222-235. doi: 10.1002/ana.21229

Fatima-Shad, K., and Barry, P. H. (1993). Anion Permeation in Gaba- and GlycineGated Channels of Mammalian Cultured Hippocampal Neurons. Proc. Biol. Sci. 253, 69-75. doi: 10.1098/rspb.1993.0083

Fernández-Nogales, M., Hernández, F., Miguez, A., Alberch, J., Ginés, S., PérezNavarro, E., et al. (2015). Decreased Glycogen Synthase Kinase-3 Levels and Activity Contribute to Huntington's Disease. Hum. Mol. Genet. 24, 5040-5052. doi: $10.1093 / \mathrm{hmg} / \mathrm{ddv} 224$

Ferrante, R. J. (2009). Mouse Models of Huntington's Disease and Methodological Considerations for Therapeutic Trials. Biochimica Biophysica Acta 1792, 506520. doi: 10.1016/j.bbadis.2009.04.001

Ferrante, R. J., Andreassen, O. A., Jenkins, B. G., Dedeoglu, A., Kuemmerle, S., Kubilus, J. K., et al. (2000). Neuroprotective Effects of Creatine in a Transgenic Mouse Model of Huntington's Disease. J. Neurosci. 20, 4389-4397. doi: 10.1523/ jneurosci.20-12-04389.2000

Foster, N. L., Chase, T. N., Denaro, A., Hare, T. A., and Tamminga, C. A. (1983). Thip Treatment of Huntington's Disease. Neurol 33, 637-639. doi: 10.1212/wnl. 33.5.637

Foster, N. N., Barry, J., Korobkova, L., Garcia, L., Gao, L., Becerra, M., et al. (2021). The Mouse Cortico-Basal Ganglia-Thalamic Network. Nature 598, 188-194. doi: 10.1038/s41586-021-03993-3

Francelle, L., Galvan, L., and Brouillet, E. (2014). Possible Involvement of SelfDefense Mechanisms in the Preferential Vulnerability of the Striatum in Huntington's Disease. Front. Cell Neurosci. 8:295. doi: 10.3389/fncel.2014.00295

Gafni, J., and Ellerby, L. M. (2002). Calpain Activation in Huntington's Disease. J. Neurosci. 22, 4842-4849. doi: 10.1523/jneurosci.22-12-04842.2002
Gafni, J., Hermel, E., Young, J. E., Wellington, C. L., Hayden, M. R., and Ellerby, L. M. (2004). Inhibition of Calpain Cleavage of Huntingtin Reduces Toxicity: Accumulation of Calpain/Caspase Fragments in the Nucleus. J. Biol. Chem. 279, 20211-20220. doi: 10.1074/jbc.M401267200

Gagnon, K. B., and Delpire, E. (2012). Molecular Physiology of Spak and Osr1: Two Ste20-Related Protein Kinases Regulating Ion Transport. Physiol. Rev. 92, 1577-1617. doi: 10.1152/physrev.00009.2012

Gagnon, K. B., England, R., and Delpire, E. (2007). A Single Binding Motif Is Required for Spak Activation of the Na-K-2cl Cotransporter. Cell Physiol. Biochem. 20, 131-142. doi: 10.1159/000104161

Gagnon, M., Bergeron, M. J., Lavertu, G., Castonguay, A., Tripathy, S., Bonin, R. P., et al. (2013). Chloride Extrusion Enhancers as Novel Therapeutics for Neurological Diseases. Nat. Med. 19, 1524-1528. doi: 10.1038/nm.3356

Gamba, G. (2005). Molecular Physiology and Pathophysiology of Electroneutral Cation-Chloride Cotransporters. Physiol. Rev. 85, 423-493. doi: 10.1152/ physrev.00011.2004

Garret, M., Du, Z., Chazalon, M., Cho, Y. H., and Baufreton, J. (2018). Alteration of Gabaergic Neurotransmission in Huntington's Disease. CNS Neurosci. Ther. 24, 292-300. doi: $10.1111 /$ cns. 12826

Gertler, T. S., Chan, C. S., and Surmeier, D. J. (2008). Dichotomous Anatomical Properties of Adult Striatal Medium Spiny Neurons. J. Neurosci. 28, 1081410824. doi: 10.1523/jneurosci.2660-08.2008

Ghosh, R., and Tabrizi, S. J. (2018). Huntington Disease. Handbook Clin. Neurol. $147,255-278$.

Goodliffe, J. W., Song, H., Rubakovic, A., Chang, W., Medalla, M., Weaver, C. M., et al. (2018). Differential Changes to D1 and D2 Medium Spiny Neurons in the 12-Month-Old Q175+/- Mouse Model of Huntington's Disease. PLoS One 13:e0200626. doi: 10.1371/journal.pone.0200626

Graybiel, A. M., and Grafton, S. T. (2015). The Striatum: Where Skills and Habits Meet. Cold Spring Harb. Perspect. Biol. 7:a021691. doi: 10.1101/cshperspect. a021691

Graybiel, A. M., Aosaki, T., Flaherty, A. W., and Kimura, M. (1994). The Basal Ganglia and Adaptive Motor Control. Science 265, 1826-1831. doi: 10.1126/ science. 8091209

Gulácsi, A., Lee, C. R., Sík, A., Viitanen, T., Kaila, K., Tepper, J. M., et al. (2003). Cell Type-Specific Differences in Chloride-Regulatory Mechanisms and Gaba(a) Receptor-Mediated Inhibition in Rat Substantia Nigra. J. Neurosci. 23, 8237-8246. doi: 10.1523/jneurosci.23-23-08237.2003

Han, X., Li, B., Ye, X., Mulatibieke, T., Wu, J., Dai, J., et al. (2017). Dopamine D(2) Receptor Signalling Controls Inflammation in Acute Pancreatitis Via a Pp2aDependent Akt/Nf-Kb Signalling Pathway. Br. J. Pharmacol. 174, 4751-4770. doi: 10.1111/bph.14057

Harjes, P., and Wanker, E. E. (2003). The Hunt for Huntingtin Function: Interaction Partners Tell Many Different Stories. Trends Biochem. Sci. 28, 425-433. doi: 10.1016/S0968-0004(03)00168-3

Hasbargen, T., Ahmed, M. M., Miranpuri, G., Li, L., Kahle, K. T., Resnick, D., et al. (2010). Role of Nkcc1 and Kcc2 in the Development of Chronic Neuropathic Pain Following Spinal Cord Injury. Ann. N Y. Acad. Sci. 1198, 168-172. doi: 10.1111/j.1749-6632.2010.05462.x

Hebert, S., and Gamba, G. (1994). Molecular Cloning and Characterization of the Renal Diuretic-Sensitive Electroneutral Sodium-(Potassium)-Chloride Cotransporters. Clin. investig. 72, 692-694. doi: 10.1007/BF00212991

Hedreen, J. C., and DeLong, M. R. (1991). Organization of Striatopallidal, Striatonigral, and Nigrostriatal Projections in the Macaque. J. Comp. Neurol. 304, 569-595. doi: 10.1002/cne.903040406

Hemmer, W., Furter-Graves, E. M., Frank, G., Wallimann, T., and Furter, R. (1995). Autophosphorylation of Creatine Kinase: Characterization and Identification of a Specifically Phosphorylated Peptide. Biochim. Biophys. Acta 1251, 81-90. doi: 10.1016/0167-4838(95)00083-7

Hodgson, J. G., Agopyan, N., Gutekunst, C. A., Leavitt, B. R., LePiane, F., Singaraja, R., et al. (1999). A Yac Mouse Model for Huntington's Disease with Full-Length Mutant Huntingtin, Cytoplasmic Toxicity, and Selective Striatal Neurodegeneration. Neuron 23, 181-192. doi: 10.1016/s0896-6273(00)80764-3

Hsu, Y. T., Chang, Y. G., and Chern, Y. (2018). Insights into Gaba(a)Ergic System Alteration in Huntington's Disease. Open Biol. 8:180165. doi: 10.1098/rsob. 180165

Hsu, Y. T., Chang, Y. G., Liu, Y. C., Wang, K. Y., Chen, H. M., Lee, D. J., et al. (2019). Enhanced $\mathrm{Na}(+)-\mathrm{K}(+)-2 \mathrm{cl}(-)$ Cotransporter 1 Underlies Motor 
Dysfunction in Huntington's Disease. Mov. Disord. 34, 845-857. doi: 10.1002/ mds. 27651

Huang, H., Song, S., Banerjee, S., Jiang, T., Zhang, J., Kahle, K. T., et al. (2019). The Wnk-Spak/Osr1 Kinases and the Cation-Chloride Cotransporters as Therapeutic Targets for Neurological Diseases. Aging Dis. 10, 626-636. doi: 10.14336/ad.2018.0928

Huguenard, J. R., and Alger, B. E. (1986). Whole-Cell Voltage-Clamp Study of the Fading of Gaba-Activated Currents in Acutely Dissociated Hippocampal Neurons. J. Neurophysiol. 56, 1-18. doi: 10.1152/jn.1986.56.1.1

Huntington, G. (1872). "On Chorea," in The Medical and Surgical Reporter: A Weekly Journal, (Virginia, VIR: American Psychiatric Publishing, Inc.).

Igarashi, P., Whyte, D. A., Li, K., and Nagami, G. T. (1996). Cloning and Kidney Cell-Specific Activity of the Promoter of the Murine Renal Na-K-C1 Cotransporter Gene. J. Biol. Chem. 271, 9666-9674. doi: 10.1074/jbc.271.16. 9666

Inoue, K., Ueno, S., and Fukuda, A. (2004). Interaction of Neuron-Specific K+Cl- Cotransporter, Kcc2, with Brain-Type Creatine Kinase. FEBS Lett. 564, 131-135. doi: 10.1016/s0014-5793(04)00328-x

Inoue, K., Yamada, J., Ueno, S., and Fukuda, A. (2006). Brain-Type Creatine Kinase Activates Neuron-Specific K+-Cl- Co-Transporter Kcc2. J. Neurochem. 96, 598-608. doi: 10.1111/j.1471-4159.2005.03560.x

Jankovic, J., and Clarence-Smith, K. (2011). Tetrabenazine for the Treatment of Chorea and Other Hyperkinetic Movement Disorders. Expert Rev. Neurother. $11,1509-1523$.

Kahle, K. T., Deeb, T. Z., Puskarjov, M., Silayeva, L., Liang, B., Kaila, K., et al. (2013). Modulation of Neuronal Activity by Phosphorylation of the K-Cl Cotransporter Kcc2. Trends Neurosci. 36, 726-737. doi: 10.1016/j.tins.2013.08.006

Kahle, K. T., Khanna, A., Clapham, D. E., and Woolf, C. J. (2014). Therapeutic Restoration of Spinal Inhibition Via Druggable Enhancement of PotassiumChloride Cotransporter Kcc2-Mediated Chloride Extrusion in Peripheral Neuropathic Pain. JAMA Neurol. 71, 640-645. doi: 10.1001/jamaneurol.2014.21

Kahle, K. T., Staley, K. J., Nahed, B. V., Gamba, G., Hebert, S. C., Lifton, R. P., et al. (2008). Roles of the Cation-Chloride Cotransporters in Neurological Disease. Nat. Clin. Pract. Neurol. 4, 490-503. doi: 10.1038/ncpneuro0883

Kaila, K. (1994). Ionic Basis of Gabaa Receptor Channel Function in the Nervous System. Prog. Neurobiol. 42, 489-537. doi: 10.1016/0301-0082(94)90049-3

Kaila, K., and Voipio, J. (1987). Postsynaptic Fall in Intracellular P H Induced by Gaba-Activated Bicarbonate Conductance. Nature 330, 163-165. doi: 10.1038/ 330163a0

Kaila, K., Lamsa, K., Smirnov, S., Taira, T., and Voipio, J. (1997). Long-Lasting Gaba-Mediated Depolarization Evoked by High-Frequency Stimulation in Pyramidal Neurons of Rat Hippocampal Slice Is Attributable to a NetworkDriven, Bicarbonate-Dependent K+ Transient. J. Neurosci. 17, 7662-7672. doi: 10.1523/jneurosci.17-20-07662.1997

Kaila, K., Pasternack, M., Saarikoski, J., and Voipio, J. (1989). Influence of Gaba-Gated Bicarbonate Conductance on Potential, Current and Intracellular Chloride in Crayfish Muscle Fibres. J. Physiol. 416, 161-181. doi: 10.1113/ jphysiol.1989.sp017755

Kaila, K., Price, T. J., Payne, J. A., Puskarjov, M., and Voipio, J. (2014). CationChloride Cotransporters in Neuronal Development, Plasticity and Disease. Nat. Rev. Neurosci. 15, 637-654. doi: 10.1038/nrn3819

Kalathur, R. K., Giner-Lamia, J., Machado, S., Barata, T., Ayasolla, K. R., and Futschik, M. E. (2015). The Unfolded Protein Response and Its Potential Role in Huntington's Disease Elucidated by a Systems Biology Approach. F1000Res 4:103. doi: 10.12688/f1000research.6358.2

Kiyomitsu, T., and Boerner, S. (2021). The Nuclear Mitotic Apparatus (Numa) Protein: A Key Player for Nuclear Formation, Spindle Assembly, and Spindle Positioning [Review]. Front. Cell Dev. Biol. 9:653801. doi: 10.3389/fcell.2021. 653801

Koós, T., and Tepper, J. M. (1999). Inhibitory Control of Neostriatal Projection Neurons by Gabaergic Interneurons. Nat. Neurosci. 2, 467-472. doi: $10.1038 / 8138$

Koumangoye, R., Bastarache, L., and Delpire, E. (2021). Nkcc1: Newly Found as a Human Disease-Causing Ion Transporter. Function 2:zqaa028. doi: 10.1093/ function/zqaa028

Kregenow, F. M. (1981). Osmoregulatory Salt Transporting Mechanisms: Control of Cell Volume in Anisotonic Media. Annu. Rev. Physiol. 43, 493-505. doi: 10.1146/annurev.ph.43.030181.002425
Lam, P. M., Carlsen, J., and González, M. I. (2017). A Calpain Inhibitor Ameliorates Seizure Burden in an Experimental Model of Temporal Lobe Epilepsy. Neurobiol. Dis. 102, 1-10. doi: 10.1016/j.nbd.2017.02.003

Lamsa, K. P., Kullmann, D. M., and Woodin, M. A. (2010). Spike-Timing Dependent Plasticity in Inhibitory Circuits. Front. Syn. Neurosci. 2:8. doi: 10. 3389/fnsyn.2010.00008

Lanciego, J. L., Luquin, N., and Obeso, J. A. (2012). Functional Neuroanatomy of the Basal Ganglia. Cold Spring Harb. Perspect. Med. 2:a009621.

Leavitt, B. R., Guttman, J. A., Hodgson, J. G., Kimel, G. H., Singaraja, R., Vogl, A. W., et al. (2001). Wild-Type Huntingtin Reduces the Cellular Toxicity of Mutant Huntingtin in Vivo. Am. J. Hum. Gen. 68, 313-324. doi: 10.1086/ 318207

Lee, H. C. (2009). Phospho-Dependent Modulation of Potassium Chloride CoTransporter Kcc2. London: University College London.

Lee, H. H., Deeb, T. Z., Walker, J. A., Davies, P. A., and Moss, S. J. (2011). Nmda Receptor Activity Downregulates Kcc2 Resulting in Depolarizing Gabaa Receptor-Mediated Currents. Nat. Neurosci. 14, 736-743. doi: 10.1038/ nn.2806

Lee, H. H., Walker, J. A., Williams, J. R., Goodier, R. J., Payne, J. A., and Moss, S. J. (2007). Direct Protein Kinase C-Dependent Phosphorylation Regulates the Cell Surface Stability and Activity of the Potassium Chloride Cotransporter Kcc2. J. Biol. Chem. 282, 29777-29784. doi: 10.1074/jbc.M705053200

Lee, H., Fenster, R. J., Pineda, S. S., Gibbs, W. S., Mohammadi, S., DavilaVelderrain, J., et al. (2020). Cell Type-Specific Transcriptomics Reveals That Mutant Huntingtin Leads to Mitochondrial Rna Release and Neuronal Innate Immune Activation. Neuron 107, 891.e-908.e. doi: 10.1016/j.neuron.2020.06. 021

Lei, W., Jiao, Y., Del Mar, N., and Reiner, A. (2004). Evidence for Differential Cortical Input to Direct Pathway Versus Indirect Pathway Striatal Projection Neurons in Rats. J. Neurosci. 24, 8289-8299. doi: 10.1523/jneurosci.1990-04. 2004

Li, H., Khirug, S., Cai, C., Ludwig, A., Blaesse, P., Kolikova, J., et al. (2007). Kcc2 Interacts with the Dendritic Cytoskeleton to Promote Spine Development. Neuron 56, 1019-1033. doi: 10.1016/j.neuron.2007.10.039

Li, H., Tornberg, J., Kaila, K., Airaksinen, M. S., and Rivera, C. (2002). Patterns of Cation-Chloride Cotransporter Expression During Embryonic Rodent Cns Development. Eur. J. Neurosci. 16, 2358-2370. doi: 10.1046/j.1460-9568.2002. 02419.x

Lim, S. A. O., and Surmeier, D. J. (2020). Enhanced Gabaergic Inhibition of Cholinergic Interneurons in the Zq175(+/-) Mouse Model of Huntington's Disease. Front. Syst. Neurosci. 14:626412. doi: 10.3389/fnsys.2020.626412

Lin, Y. S., Cheng, T. H., Chang, C. P., Chen, H. M., and Chern, Y. (2013). Enhancement of Brain-Type Creatine Kinase Activity Ameliorates Neuronal Deficits in Huntington's Disease. Biochim. Biophys. Acta 1832, 742-753. doi: 10.1016/j.bbadis.2013.02.006

Liu, S., Chang, S., Han, B., Xu, L., Zhang, M., Zhao, C., et al. (2019b). Cryo-Em Structures of the Human Cation-Chloride Cotransporter Kccl. Science 366, 505-508. doi: 10.1126/science.aay3129

Liu, R., Wang, J., Liang, S., Zhang, G., and Yang, X. (2019a). Role of Nkcc1 and Kcc2 in Epilepsy: From Expression to Function. Front. Neurol 10:1407. doi: 10.3389/fneur.2019.01407

Lozovaya, N., Eftekhari, S., Cloarec, R., Gouty-Colomer, L. A., Dufour, A., Riffault, B., et al. (2018). Gabaergic Inhibition in Dual-Transmission Cholinergic and Gabaergic Striatal Interneurons Is Abolished in Parkinson Disease. Nat. Comm. 9:1422. doi: 10.1038/s41467-018-03802-y

Ludwig, A., Uvarov, P., Soni, S., Thomas-Crusells, J., Airaksinen, M. S., and Rivera, C. (2011). Early Growth Response 4 Mediates Bdnf Induction of Potassium Chloride Cotransporter 2 Transcription. J. Neurosci. 31, 644-649. doi: 10.1523/ jneurosci.2006-10.2011

Mahadevan, V., Khademullah, C. S., Dargaei, Z., Chevrier, J., Uvarov, P., Kwan, J., et al. (2017). Native Kcc2 Interactome Reveals Pacsin 1 as a Critical Regulator of Synaptic Inhibition. Elife 6:28270. doi: 10.7554/eLife.28270

Mangiarini, L., Sathasivam, K., Seller, M., Cozens, B., Harper, A., Hetherington, C., et al. (1996). Exon 1 of the Hd Gene with an Expanded Cag Repeat Is Sufficient to Cause a Progressive Neurological Phenotype in Transgenic Mice. Cell 87, 493-506. doi: 10.1016/s0092-8674(00)81369-0

Marco, S., Giralt, A., Petrovic, M. M., Pouladi, M. A., Martínez-Turrillas, R., Martínez-Hernández, J., et al. (2013). Suppressing Aberrant Glun3a Expression 
Rescues Synaptic and Behavioral Impairments in Huntington's Disease Models. Nat. Med. 19, 1030-1038. doi: 10.1038/nm.3246

Maue, R., Kraner, S., Goodman, R., and Mandelt, G. (1990). Neuron-Specific Expression of the Rat Brain Type Ii Sodium Channel Gene Is Directed by Upstream Regulatory Elements. Neuron 4, 223-231. doi: 10.1016/08966273(90)90097-y

Mazarati, A., Shin, D., and Sankar, R. (2009). Bumetanide Inhibits Rapid Kindling in Neonatal Rats. Epilepsia 50, 2117-2122. doi: 10.1111/j.1528-1167.2009. 02048.x

Menalled, L. B., and Chesselet, M. F. (2002). Mouse Models of Huntington's Disease. Trends Pharmacol. Sci. 23, 32-39. doi: 10.1016/s0165-6147(00)01884-8

Mercado, A., Broumand, V., Zandi-Nejad, K., Enck, A. H., and Mount, D. B. (2006). A C-Terminal Domain in Kcc2 Confers Constitutive $\mathrm{K}+-\mathrm{Cl}-$ Cotransport. J. Bio. Chem. 281, 1016-1026. doi: 10.1074/jbc.M509972200

Mochel, F., Durant, B., Meng, X., O'Callaghan, J., Yu, H., Brouillet, E., et al. (2012). Early Alterations of Brain Cellular Energy Homeostasis in Huntington Disease Models. J. Biol. Chem. 287, 1361-1370. doi: 10.1074/jbc.M111.309849

Modregger, J., DiProspero, N. A., Charles, V., Tagle, D. A., and Plomann, M. (2002). Pacsin 1 Interacts with Huntingtin and Is Absent from Synaptic Varicosities in Presymptomatic Huntington's Disease Brains. Hum. Mol. Gen. 11, 2547-2558. doi: $10.1093 / \mathrm{hmg} / 11.21 .2547$

Moore, Y. E., Kelley, M. R., Brandon, N. J., Deeb, T. Z., and Moss, S. J. (2017). Seizing Control of Kcc2: A New Therapeutic Target for Epilepsy. Trends Neurosci. 40, 555-571. doi: 10.1016/j.tins.2017.06.008

Mueller, A. L., Taube, J. S., and Schwartzkroin, P. A. (1984). Development of Hyperpolarizing Inhibitory Postsynaptic Potentials and Hyperpolarizing Response to Gamma-Aminobutyric Acid in Rabbit Hippocampus Studied in Vitro. J. Neurosci. 4, 860-867. doi: 10.1523/jneurosci.04-03-00860.1984

Nakao, N., Brundin, P., Funa, K., Lindvall, O., and Odin, P. (1995). Trophic and Protective Actions of Brain-Derived Neurotrophic Factor on Striatal Darpp-32Containing Neurons in Vitro. Dev. Brain Res. 90, 92-101. doi: 10.1016/01653806(96)83489-4

Ono, Y., Saido, T. C., and Sorimachi, H. (2016). Calpain Research for Drug Discovery: Challenges and Potential. Nat. Rev. Drug Discov. 15, 854-876. doi: 10.1038/nrd.2016.212

Paulsen, J. S., Langbehn, D. R., Stout, J. C., Aylward, E., Ross, C. A., Nance, M., et al. (2008). Detection of Huntington's Disease Decades before Diagnosis: The Predict-Hd Study. J. Neurol. Neurosurg. Psych. 79, 874-880. doi: 10.1136/jnnp. 2007.128728

Payne, J. A. (1997). Functional Characterization of the Neuronal-Specific K-Cl Cotransporter: Implications for [K+] O Regulation. Am. J. Physiol. 273, C1516C1525. doi: 10.1152/ajpcell.1997.273.5.C1516

Pérez-Otaño, I., Luján, R., Tavalin, S. J., Plomann, M., Modregger, J., Liu, X.-B., et al. (2006). Endocytosis and Synaptic Removal of Nr3a-Containing Nmda Receptors by Pacsin1/Syndapin1. Nat. Neurosci. 9, 611-621. doi: 10.1038/ nn1680

Perry, T. L., Hansen, S., and Kloster, M. (1973). Huntington's Chorea. Deficiency of Gamma-Aminobutyric Acid in Brain. N. Engl. J. Med. 288, 337-342. doi: 10.1056/nejm197302152880703

Phillips, R. S., Rosner, I., Gittis, A. H., and Rubin, J. E. (2020). The Effects of Chloride Dynamics on Substantia Nigra Pars Reticulata Responses to Pallidal and Striatal Inputs. Elife 9:55592. doi: 10.7554/eLife.55592

Plenz, D. (2003). When Inhibition Goes Incognito: Feedback Interaction between Spiny Projection Neurons in Striatal Function. Trends Neurosci. 26, 436-443. doi: 10.1016/s0166-2236(03)00196-6

Plenz, D., and Kitai, S. T. (1998). Up and Down States in Striatal Medium Spiny Neurons Simultaneously Recorded with Spontaneous Activity in Fast-Spiking Interneurons Studied in Cortex-Striatum-Substantia Nigra Organotypic Cultures. J. Neurosci. 18, 266-283. doi: 10.1523/ineurosci.18-01-00266.1998

Plenz, D., and Kital, S. T. (1999). A Basal Ganglia Pacemaker Formed by the Subthalamic Nucleus and External Globus Pallidus. Nature 400, 677-682. doi $10.1038 / 23281$

Plotkin, J. L., and Goldberg, J. A. (2019). Thinking Outside the Box (and Arrow): Current Themes in Striatal Dysfunction in Movement Disorders. Neuroscientist 25, 359-379. doi: 10.1177/1073858418807887

Pradhan, J., Noakes, P. G., and Bellingham, M. C. (2019). The Role of Altered Bdnf/Trkb Signaling in Amyotrophic Lateral Sclerosis. Front. Cell Neurosci. 13:368. doi: 10.3389/fncel.2019.00368
Prescott, S. A., Sejnowski, T. J., and De Koninck, Y. (2006). Reduction of Anion Reversal Potential Subverts the Inhibitory Control of Firing Rate in Spinal Lamina I Neurons: Towards a Biophysical Basis for Neuropathic Pain. Mol. Pain 2:32. doi: 10.1186/1744-8069-2-32

Puskarjov, M., Ahmad, F., Kaila, K., and Blaesse, P. (2012). Activity-Dependent Cleavage of the K-Cl Cotransporter Kcc2 Mediated by Calcium-Activated Protease Calpain. J. Neurosci. 32, 11356-11364. doi: 10.1523/jneurosci.6265-11. 2012

Puskarjov, M., Kahle, K. T., Ruusuvuori, E., and Kaila, K. (2014). Pharmacotherapeutic Targeting of Cation-Chloride Cotransporters in Neonatal Seizures. Epilepsia 55, 806-818. doi: 10.1111/epi.12620

Raimondo, J. V., Markram, H., and Akerman, C. J. (2012). Short-Term Ionic Plasticity at Gabaergic Synapses. Front. Syn. Neurosci. 4:5. doi: 10.3389/fnsyn. 2012.00005

Raymond, L. A., André, V. M., Cepeda, C., Gladding, C. M., Milnerwood, A. J., and Levine, M. S. (2011). Pathophysiology of Huntington's Disease: TimeDependent Alterations in Synaptic and Receptor Function. Neurosci. 198, 252-273. doi: 10.1016/j.neuroscience.2011.08.052

Reiner, A., Albin, R. L., Anderson, K. D., D’Amato, C. J., Penney, J. B., and Young, A. B. (1988). Differential Loss of Striatal Projection Neurons in Huntington Disease. Proc. Nat. Acad. Sci. 85, 5733-5737. doi: 10.1073/pnas.85.15.5733

Reynolds, G. P., and Pearson, S. J. (1987). Decreased Glutamic Acid and Increased 5-Hydroxytryptamine in Huntington's Disease Brain. Neurosci. Lett. 78, $233-$ 238. doi: 10.1016/0304-3940(87)90639-2

Rinehart, J., Maksimova, Y. D., Tanis, J. E., Stone, K. L., Hodson, C. A., Zhang, J., et al. (2009). Sites of Regulated Phosphorylation That Control K-Cl Cotransporter Activity. Cell 138, 525-536. doi: 10.1016/j.cell.2009.05.031

Rivera, C., Li, H., Thomas-Crusells, J., Lahtinen, H., Viitanen, T., Nanobashvili, A., et al. (2002). Bdnf-Induced Trkb Activation Down-Regulates the $\mathrm{K}+\mathrm{Cl}-$ Cotransporter Kcc2 and Impairs Neuronal Cl- Extrusion. J. Cell Biol. 159, 747-752. doi: 10.1083/jcb.200209011

Rivera, C., Voipio, J., and Kaila, K. (2005). Two Developmental Switches in Gabaergic Signalling: The K+-Cl- Cotransporter Kcc2 and Carbonic Anhydrase Cavii. J. Physiol. 562, 27-36. doi: 10.1113/jphysiol.2004.077495

Rivera, C., Voipio, J., Payne, J. A., Ruusuvuori, E., Lahtinen, H., Lamsa, K., et al. (1999). The K+/Cl- Co-Transporter Kcc2 Renders Gaba Hyperpolarizing During Neuronal Maturation. Nature 397, 251-255. doi: 10.1038/16697

Rivera, C., Voipio, J., Thomas-Crusells, J., Li, H., Emri, Z., Sipilä, S., et al. (2004). Mechanism of Activity-Dependent Downregulation of the Neuron-Specific K-Cl Cotransporter Kcc2. J. Neurosci. 24, 4683-4691. doi: 10.1523/jneurosci. 5265-03.2004

Römermann, K., Fedrowitz, M., Hampel, P., Kaczmarek, E., Töllner, K., Erker, T., et al. (2017). Multiple Blood-Brain Barrier Transport Mechanisms Limit Bumetanide Accumulation, and Therapeutic Potential, in the Mammalian Brain. Neuropharm 117, 182-194. doi: 10.1016/j.neuropharm.2017.02.006

Russell, J. M. (2000). Sodium-Potassium-Chloride Cotransport. Physiol. Rev. 80, 211-276. doi: 10.1152/physrev.2000.80.1.211

Ruusuvuori, E., Li, H., Huttu, K., Palva, J. M., Smirnov, S., Rivera, C., et al. (2004). Carbonic Anhydrase Isoform Vii Acts as a Molecular Switch in the Development of Synchronous Gamma-Frequency Firing of Hippocampal Ca1 Pyramidal Cells. J. Neurosci. 24, 2699-2707. doi: 10.1523/JNEUROSCI.5176-03. 2004

Sallinen, R., Tornberg, J., Putkiranta, M., Horelli-Kuitunen, N., Airaksinen, M. S., and Wessman, M. (2001). Chromosomal Localization of Slc12a5/Slc12a5, the Human and Mouse Genes for the Neuron-Specific K+-Cl-Cotransporter (Kcc2) Defines a New Region of Conserved Homology. Cytogen. Gen. Res. 94, 67-70. doi: $10.1159 / 000048785$

Saudou, F., and Humbert, S. (2016). The Biology of Huntingtin. Neuron 89, 910-926. doi: 10.1016/j.neuron.2016.02.003

Savardi, A., Borgogno, M., De Vivo, M., and Cancedda, L. (2021). Pharmacological Tools to Target Nkccl in Brain Disorders. Trends Pharmacol. Sci 42, 1009-1034. doi: 10.1016/j.tips.2021.09.005

Savardi, A., Borgogno, M., Narducci, R., La Sala, G., Ortega, J. A., Summa, M., et al. (2020). Discovery of a Small Molecule Drug Candidate for Selective Nkcc1 Inhibition in Brain Disorders. Chem 6, 2073-2096. doi: 10.1016/j.chempr.2020. 06.017

Shirasaki, D. I., Greiner, E. R., Al-Ramahi, I., Gray, M., Boontheung, P., Geschwind, D. H., et al. (2012). Network Organization of the Huntingtin Proteomic 
Interactome in Mammalian Brain. Neuron 75, 41-57. doi: 10.1016/j.neuron. 2012.05.024

Shoulson, I., Goldblatt, D., Charlton, M., and Joynt, R. J. (1977). Huntington's Disease: Treatment with Muscimol, a Gaba-Mimetic Drug. Trans Am. Neurol. Assoc. 102, 124-125.

Snell, R. G., MacMillan, J. C., Cheadle, J. P., Fenton, I., Lazarou, L. P., Davies, P., et al. (1993). Relationship between Trinucleotide Repeat Expansion and Phenotypic Variation in Huntington's Disease. Nat. Gen. 4, 393-397. doi: 10. 1038/ng0893-393

Spargo, E., Everall, I., and Lantos, P. (1993). Neuronal Loss in the Hippocampus in Huntington's Disease: A Comparison with Hiv Infection. J. Neurol. Neurosurg. Psych. 56, 487-491. doi: 10.1136/jnnp.56.5.487

Spokes, E. G. (1980). Neurochemical Alterations in Huntington's Chorea: A Study of Post-Mortem Brain Tissue. Brain 103, 179-210. doi: 10.1093/brain/103.1.179

Spokes, E. G., Garrett, N. J., Rossor, M. N., and Iversen, L. L. (1980). Distribution of Gaba in Post-Mortem Brain Tissue from Control, Psychotic and Huntington's Chorea Subjects. J. Neurol. Sci. 48, 303-313. doi: $10.1016 / 0022-510 x(80) 90103-3$

Sturrock, A., and Leavitt, B. R. (2010). The Clinical and Genetic Features of Huntington Disease. J. Ger. Psych. Neurol. 23, 243-259.

Surmeier, D. J., Ding, J., Day, M., Wang, Z., and Shen, W. (2007). D1 and D2 Dopamine-Receptor Modulation of Striatal Glutamatergic Signaling in Striatal Medium Spiny Neurons. Trends Neurosci. 30, 228-235. doi: 10.1016/j.tins.2007. 03.008

Takayama, C., and Inoue, Y. (2007). Developmental Localization of Potassium Chloride Co-Transporter 2 (Kcc2) in the Purkinje Cells of Embryonic Mouse Cerebellum. Neurosci. Res. 57, 322-325. doi: 10.1016/j.neures.2006.10.016

Tang, B. L. (2020). The Expanding Therapeutic Potential of Neuronal Kcc2. Cells 9:240. doi: 10.3390/cells9010240

Tang, X., Drotar, J., Li, K., Clairmont, C. D., Brumm, A. S., Sullins, A. J., et al. (2019). Pharmacological Enhancement of Kcc2 Gene Expression Exerts Therapeutic Effects on Human Rett Syndrome Neurons and Mecp2 Mutant Mice. Sci. Transl. Med. 11:aau0164. doi: 10.1126/scitranslmed.aau0164

Tang, X., Kim, J., Zhou, L., Wengert, E., Zhang, L., Wu, Z., et al. (2016). Kcc2 Rescues Functional Deficits in Human Neurons Derived from Patients with Rett Syndrome. Proc. Natl. Acad. Sci. U S A. 113, 751-756. doi: 10.1073/pnas. 1524013113

Tecuapetla, F., Koós, T., Tepper, J. M., Kabbani, N., and Yeckel, M. F. (2009). Differential Dopaminergic Modulation of Neostriatal Synaptic Connections of Striatopallidal Axon Collaterals. J. Neurosci. 29, 8977-8990. doi: 10.1523/ jneurosci.6145-08.2009

Tepper, J. M., and Plenz, D. (2004). Microcircuits in the Striatum Striatal Cell Types and Their Interaction. Berlin: ResearchGate.

The Huntington's Disease Collaborative Research Group (1993). A Novel Gene Containing a Trinucleotide Repeat That Is Expanded and Unstable on Huntington's Disease Chromosomes. The Huntington's Disease Collaborative Research Group. Cell 72, 971-983. doi: 10.1016/0092-8674(93)90585-e

Thompson, P., Berardelli, A., Rothwell, J., Day, B., Dick, J., Benecke, R., et al. (1988). The Coexistence of Bradykinesia and Chorea in Huntington's Disease and Its Implications for Theories of Basal Ganglia Control of Movement. Brain 111, 223-244. doi: 10.1093/brain/111.2.223

Thompson, S. M., and Gähwiler, B. H. (1989). Activity-Dependent Disinhibition. I. Repetitive Stimulation Reduces Ipsp Driving Force and Conductance in the Hippocampus in Vitro. J. Neurophysiol. 61, 501-511. doi: 10.1152/jn.1989.61.3.501

Tong, X., Ao, Y., Faas, G. C., Nwaobi, S. E., Xu, J., Haustein, M. D., et al. (2014). Astrocyte Kir4.1 Ion Channel Deficits Contribute to Neuronal Dysfunction in Huntington's Disease Model Mice. Nat. Neurosci. 17, 694-703. doi: 10.1038/nn. 3691

Tritsch, N. X., Ding, J. B., and Sabatini, B. L. (2012). Dopaminergic Neurons Inhibit Striatal Output through Non-Canonical Release of Gaba. Nature 490, 262-266. doi: 10.1038/nature11466

Urquhart, N., Perry, T. L., Hansen, S., and Kennedy, J. (1975). Gaba Content and Glutamic Acid Decarboxylase Activity in Brain of Huntington's Chorea Patients and Control Subjects. J. Neurochem. 24, 1071-1075. doi: 10.1111/j.1471-4159. 1975.tb03679.x

Uvarov, P., Ludwig, A., Markkanen, M., Rivera, C., and Airaksinen, M. S. (2006). Upregulation of the Neuron-Specific $\mathrm{K}+/ \mathrm{Cl}$ - Cotransporter Expression by
Transcription Factor Early Growth Response 4. J. Neurosci. 26, 13463-13473. doi: 10.1523/jneurosci.4731-06.2006

Valeeva, G., Tressard, T., Mukhtarov, M., Baude, A., and Khazipov, R. (2016). An Optogenetic Approach for Investigation of Excitatory and Inhibitory Network Gaba Actions in Mice Expressing Channelrhodopsin-2 in Gabaergic Neurons. J. Neurosci. 36, 5961-5973. doi: 10.1523/jneurosci.3482-15.2016

Vicini, S., Ferguson, C., Prybylowski, K., Kralic, J., Morrow, A. L., and Homanics, G. E. (2001). Gaba(a) Receptor Alphal Subunit Deletion Prevents Developmental Changes of Inhibitory Synaptic Currents in Cerebellar Neurons. J. Neurosci. 21, 3009-3016. doi: 10.1523/jneurosci.21-09-03009.2001

Virtanen, M. A., Uvarov, P., Mavrovic, M., Poncer, J. C., and Kaila, K. (2021). The Multifaceted Roles of Kcc2 in Cortical Development. Trends Neurosci. 44, 378-392. doi: 10.1016/j.tins.2021.01.004

Vonsattel, J. P. G., and DiFiglia, M. (1998). Huntington Disease. J. Neuropath. Exp. Neurol. 57:369.

Wan, L., Ren, L., Chen, L., Wang, G., Liu, X., Wang, B. H., et al. (2018). MCalpain Activation Facilitates Seizure Induced Kcc2 Down Regulation. Front. Mol. Neurosci. 11:287. doi: 10.3389/fnmol.2018.00287

Wang, C., Shimizu-Okabe, C., Watanabe, K., Okabe, A., Matsuzaki, H., Ogawa, T., et al. (2002). Developmental Changes in Kcc1, Kcc2, and Nkcc1 Mrna Expressions in the Rat Brain. Brain Res. Dev. Brain Res. 139, 59-66. doi: 10. 1016/s0165-3806(02)00536-9

Watanabe, M., and Fukuda, A. (2015). Development and Regulation of Chloride Homeostasis in the Central Nervous System. Front. Cell Neurosci. 9:371. doi: $10.3389 /$ fncel.2015.00371

Watanabe, M., Zhang, J., Mansuri, M. S., Duan, J., Karimy, J. K., Delpire, E., et al. (2019). Developmentally Regulated Kcc2 Phosphorylation Is Essential for Dynamic Gaba-Mediated Inhibition and Survival. Sci. Signal 12:aaw9315. doi: 10.1126/scisignal.aaw9315

Weidenfeld, S., and Kuebler, W. M. (2017). Cytokine-Regulation of $\mathrm{Na}(+)-$ $\mathrm{K}(+)-\mathrm{Cl}(-)$ Cotransporter 1 and Cystic Fibrosis Transmembrane Conductance Regulator-Potential Role in Pulmonary Inflammation and Edema Formation. Front. Immunol 8:393. doi: 10.3389/fimmu.2017.00393

Wiggins, R., and Feigin, A. (2021). Emerging Therapeutics in Huntington's Disease. Expert. Opin. Emerg. Drugs 26, 295-302.

Willett, J. A., Cao, J., Dorris, D. M., Johnson, A. G., Ginnari, L. A., and Meitzen, J. (2019). Electrophysiological Properties of Medium Spiny Neuron Subtypes in the Caudate-Putamen of Prepubertal Male and Female Drd1a-Tdtomato Line 6 Bac Transgenic Mice. eNeuro 6:2019. doi: 10.1523/eneuro.0016-19.2019

Williams, J. R., Sharp, J. W., Kumari, V. G., Wilson, M., and Payne, J. A. (1999). The Neuron-Specific K-Cl Cotransporter, Kcc2. J. Bio. Chem. 274, 12656-12664.

Wilson, C. J. (1992). Dendritic Morphology, Inward Rectification, and the Functional Properties of Neostriatal Neurons. Elsevier 1992, 141-171. doi: 10. 1016/s0306-4522(01)00506-1

Wilson, C. J., and Kawaguchi, Y. (1996). The Origins of Two-State Spontaneous Membrane Potential Fluctuations of Neostriatal Spiny Neurons. J. Neurosci. 16, 2397-2410. doi: 10.1523/jneurosci.16-07-02397.1996

Wojtecki, L., Groiss, S. J., Hartmann, C. J., Elben, S., Omlor, S., Schnitzler, A., et al. (2016). Deep Brain Stimulation in Huntington's Disease-Preliminary Evidence on Pathophysiology, Efficacy and Safety. Brain Sci. 6:brainsci6030038. doi: 10.3390/brainsci6030038

Wójtowicz, A. M., Dvorzhak, A., Semtner, M., and Grantyn, R. (2013). Reduced Tonic Inhibition in Striatal Output Neurons from Huntington Mice Due to Loss of Astrocytic Gaba Release through Gat-3. Front. Neur. Circ. 7:188. doi: 10.3389/fncir.2013.00188

Woodin, M. A., Ganguly, K., and Poo, M. M. (2003). Coincident Pre- and Postsynaptic Activity Modifies Gabaergic Synapses by Postsynaptic Changes in Cl- Transporter Activity. Neuron 39, 807-820. doi: 10.1016/s0896-6273(03) 00507-5

Yang, X., Wang, Q., and Cao, E. (2020). Structure of the Human CationChloride Cotransporter Nkcc1 Determined by Single-Particle Electron CryoMicroscopy. Nat. Comm. 11, 1-11.

Yeo, M., Berglund, K., Augustine, G., and Liedtke, W. (2009). Novel Repression of Kcc2 Transcription by Rest-Re-1 Controls Developmental Switch in Neuronal Chloride. J. Neurosci. 29, 14652-14662. doi: 10.1523/jneurosci.2934-09.2009

Yeo, M., Chen, Y., Jiang, C., Chen, G., Wang, K., Chandra, S., et al. (2021). Repurposing Cancer Drugs Identifies Kenpaullone Which Ameliorates 
Pathologic Pain in Preclinical Models Via Normalization of Inhibitory Neurotransmission. Nat. Comm. 12:6208. doi: 10.1038/s41467-021-26270-3

Zeitlin, S., Liu, J.-P., Chapman, D. L., Papaioannou, V. E., and Efstratiadis, A. (1995). Increased Apoptosis and Early Embryonic Lethality in Mice Nullizygous for the Huntington's Disease Gene Homologue. Nat. Gen. 11, 155-163.

Zhang, J., Bhuiyan, M. I. H., Zhang, T., Karimy, J. K., Wu, Z., Fiesler, V. M., et al. (2020). Modulation of Brain Cation-Cl(-) Cotransport Via the Spak Kinase Inhibitor Zt-1a. Nat. Comm. 11:78. doi: 10.1038/s41467-019-13851-6

Zhang, S., Zhou, J., Zhang, Y., Liu, T., Friedel, P., Zhuo, W., et al. (2021). The Structural Basis of Function and Regulation of Neuronal Cotransporters Nkcc1 and Kcc2. Comm. Biol. 4, 1-15.

Zilberter, M. (2016). Reality of Inhibitory Gaba in Neonatal Brain: Time to Rewrite the Textbooks? J. Neurosci. 36, 10242-10244. doi: 10.1523/jneurosci.2270-16. 2016

Zuccato, C., Tartari, M., Crotti, A., Goffredo, D., Valenza, M., Conti, L., et al. (2003). Huntingtin Interacts with Rest/Nrsf to Modulate the Transcription of Nrse-Controlled Neuronal Genes. Nat. Gen. 35, 76-83.
Conflict of Interest: The authors declare that the research was conducted in the absence of any commercial or financial relationships that could be construed as a potential conflict of interest.

Publisher's Note: All claims expressed in this article are solely those of the authors and do not necessarily represent those of their affiliated organizations, or those of the publisher, the editors and the reviewers. Any product that may be evaluated in this article, or claim that may be made by its manufacturer, is not guaranteed or endorsed by the publisher.

Copyright $\odot 2022$ Serranilla and Woodin. This is an open-access article distributed under the terms of the Creative Commons Attribution License (CC BY). The use, distribution or reproduction in other forums is permitted, provided the original author(s) and the copyright owner(s) are credited and that the original publication in this journal is cited, in accordance with accepted academic practice. No use, distribution or reproduction is permitted which does not comply with these terms. 